مؤشرات الوضع الراهن لمتطلبات السكان

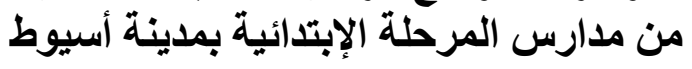

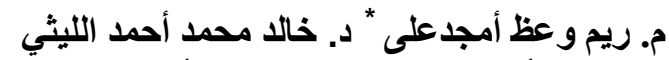

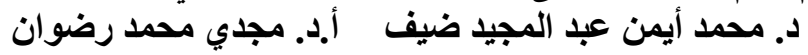

أعضاء هيئة تدربيس بقسم الهندسة المعدارية، كلبة المهندسة، جامعة أسبيوط.

Received 22 January 2014; accepted 29 February 2014

الملخص

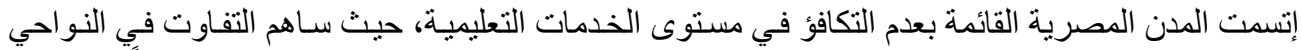

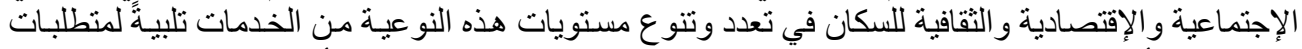

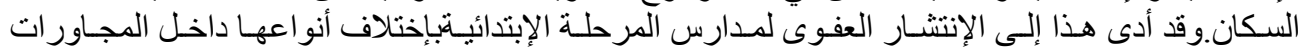

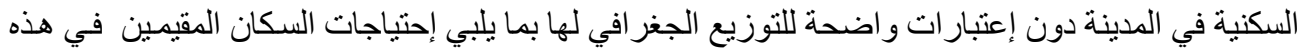

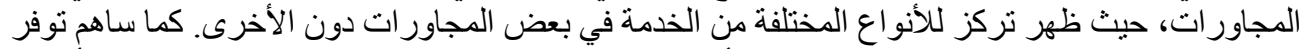

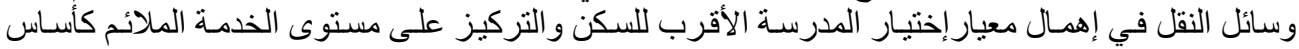

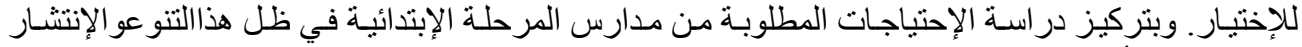

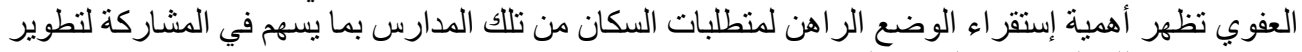

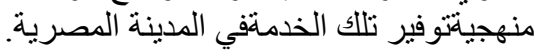

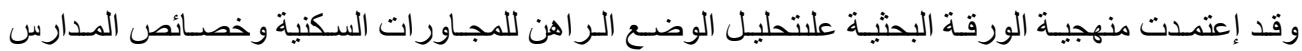

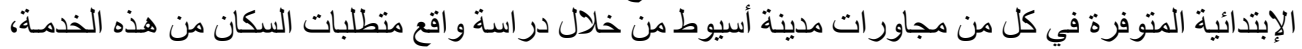

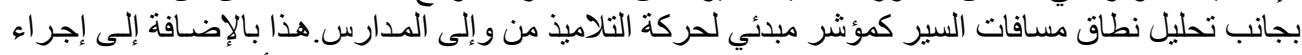

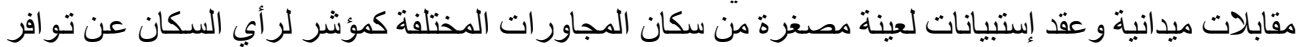

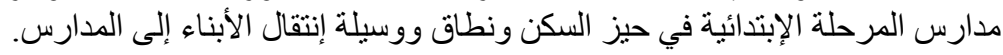

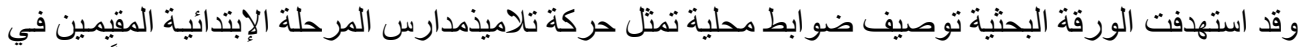

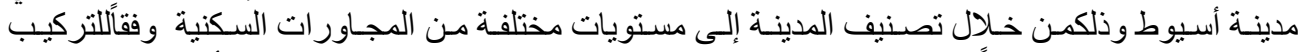

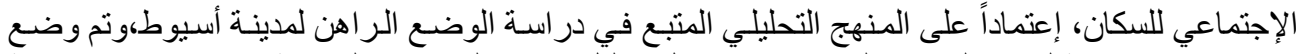

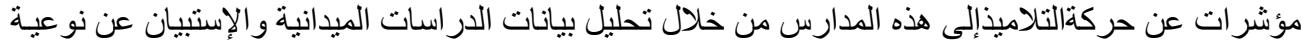

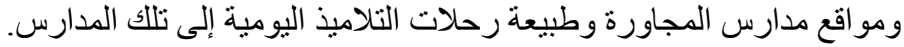

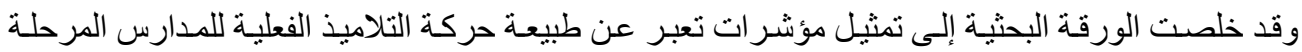

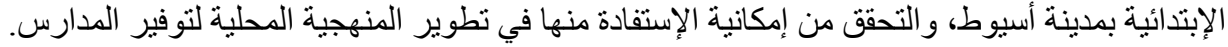

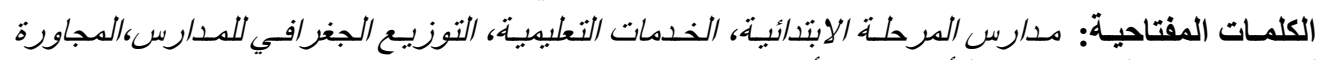

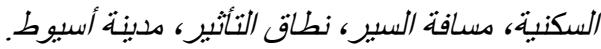

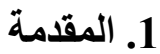

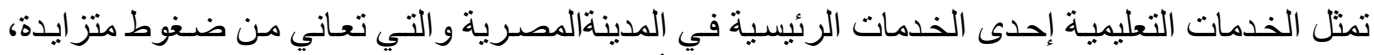

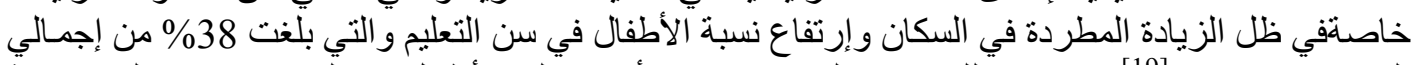

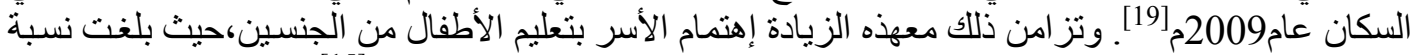

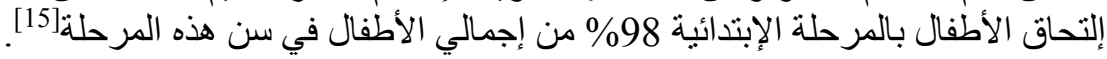

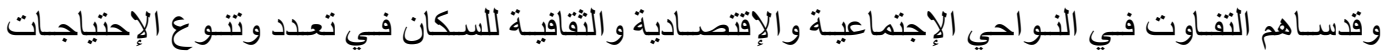

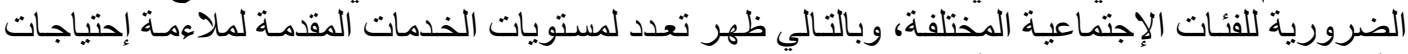

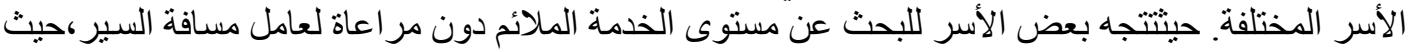

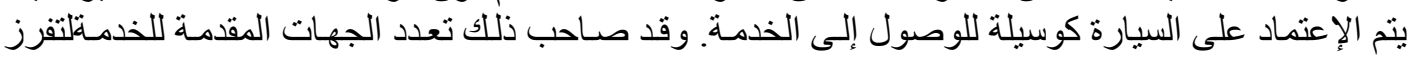


ريج وعظ أمجدعلى، خالد محد أحدد الليثي، محد أيمن عبد المجيب ضيف و مجدي محد رضوان

تنو عـاً في مسـتويات وأسـلوب التعليم في أنمـاط متنو عـة مـن المـدارس تمثلت في في مـدارس حكوميـة (عامسة وتجريبية) و معاهد أز هرية ومدارس خاصنة (ذات تبعيات متنو عة) لمر احل التعليم المختلفة.

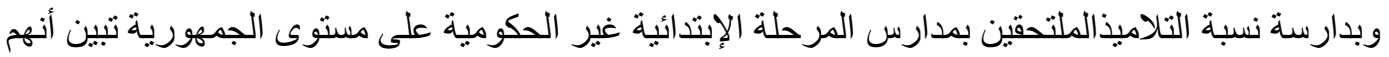

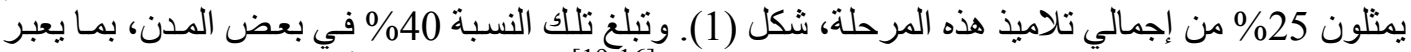

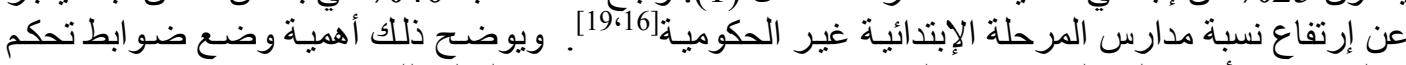
عمليةتوفير الأنواع المختلفة من هذه المدارسبما يتلاءم مع الإحتياجات الفحلية للسكان.

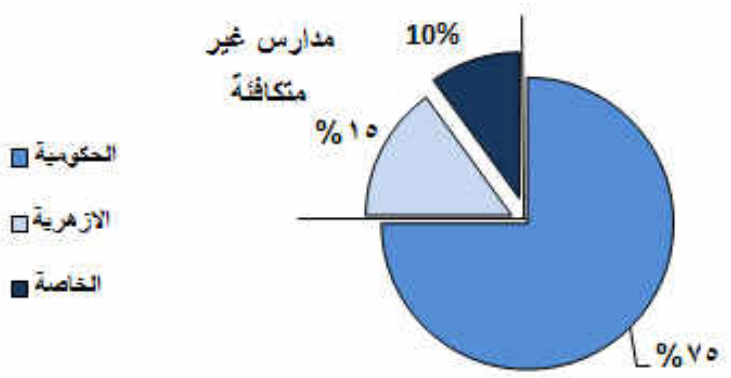

شكل رقم (1): نسب التلاميذ في مدارس المرحلة الإبتدائية المختلفة من إجمالي التلاميذ في مصر [16]

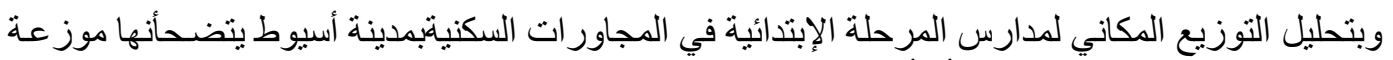

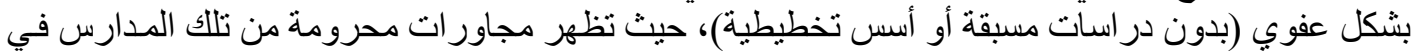

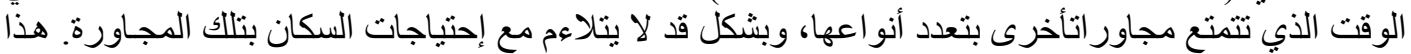

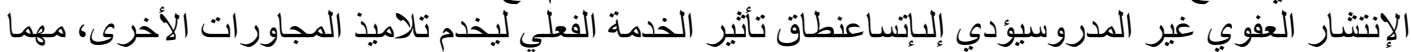

تباعدت مو اقعها مما يزيد من حجم مشكلات الحركة الإنيات بالمدينة. 1.1 الإشكالبة البحثبية

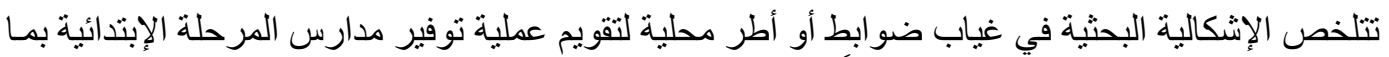

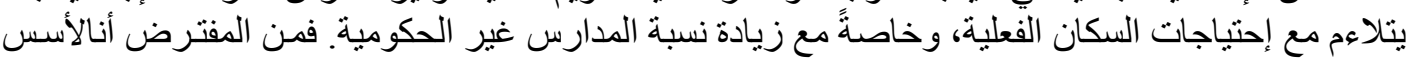

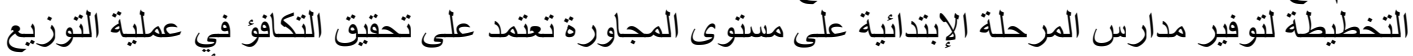

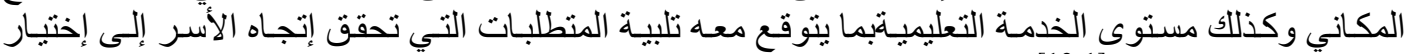

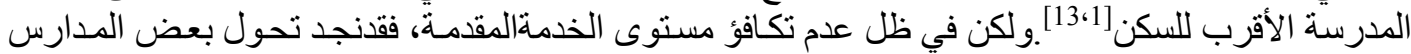

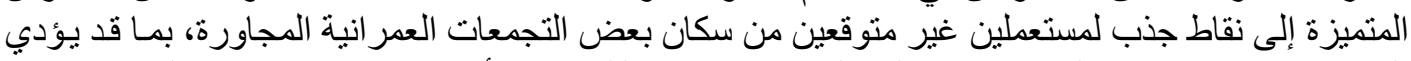

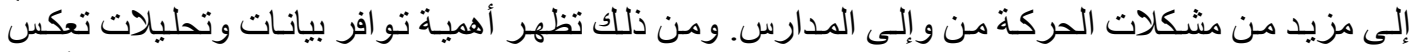

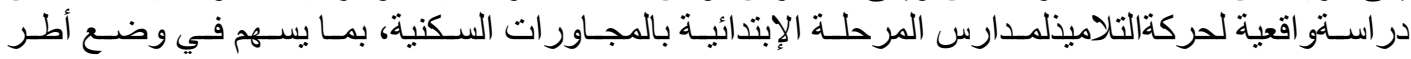

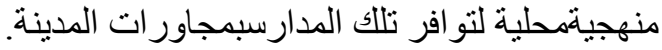
2.1

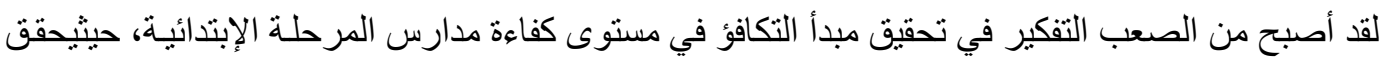

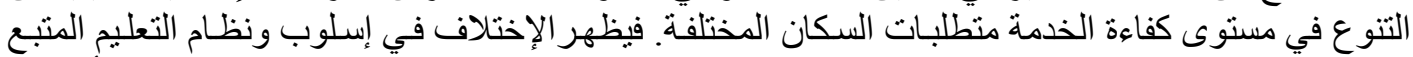

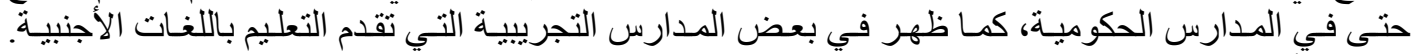

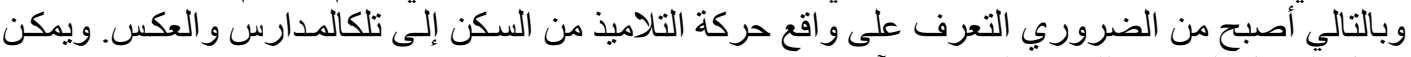
تمثيل الَّؤال الرئيسي للورقية البروي البحثية كالآتي:

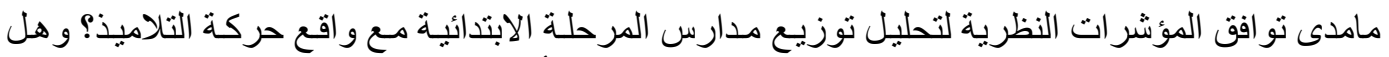
يمكن تطوير هالتتلاعم معإحتياجات السكان المقيمينبمجاورات مدينة مدئة أسيوط من مدارس هذه المرحلة؟ 


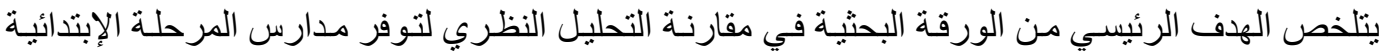

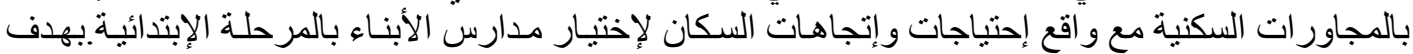

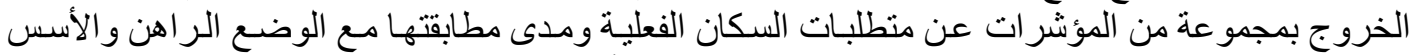

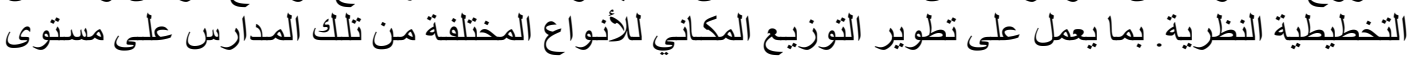
المجاور ات السكنية بالمدينة، والمساهمة في تطوير المعايير التخطيطية المحلية. 4.1

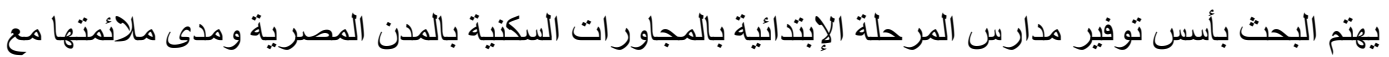

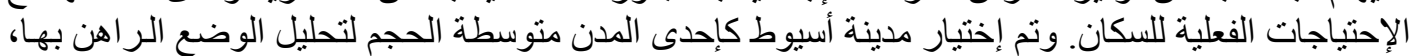

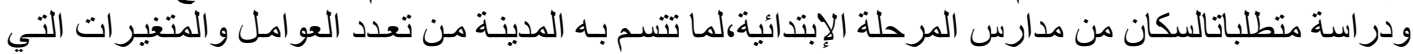

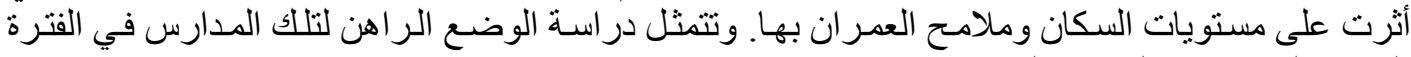

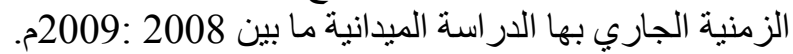

$$
\text { 5.1 }
$$

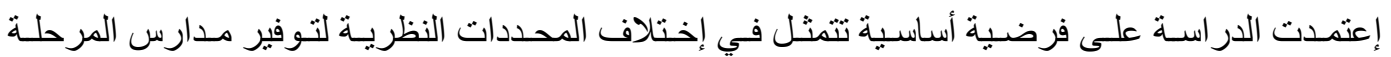

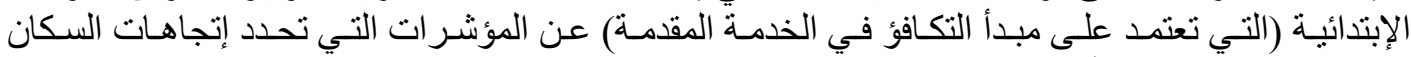
الفعليةلإختيار مدارس الأبناء.

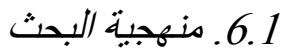

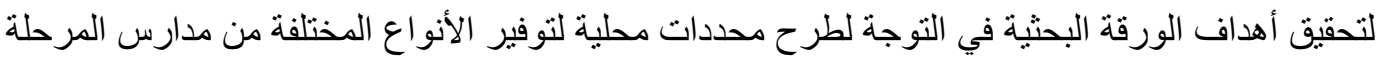

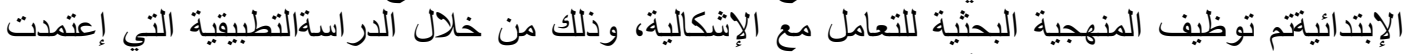

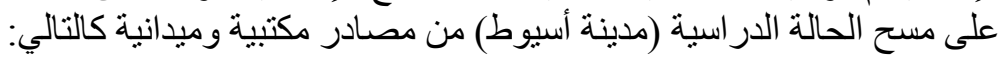

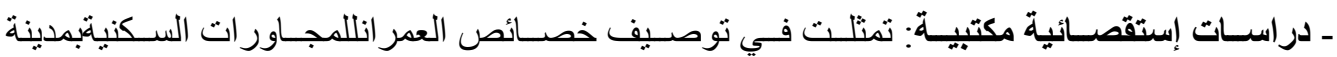

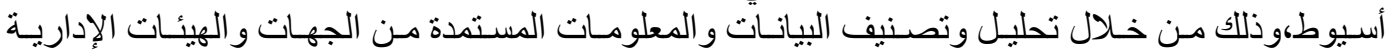

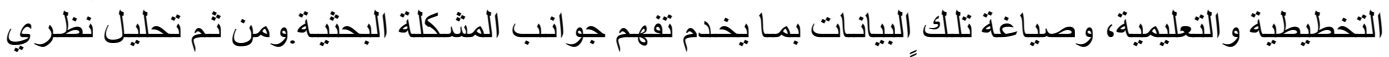

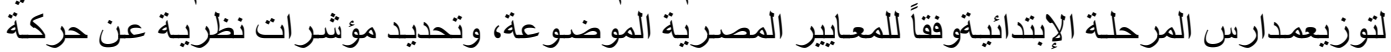
التلاميذ من و إلى تلإنك الخدمة.

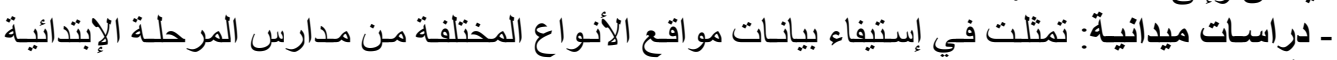

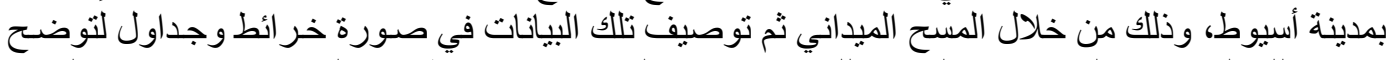

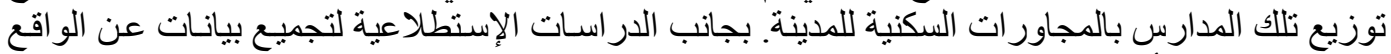

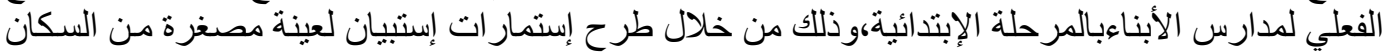

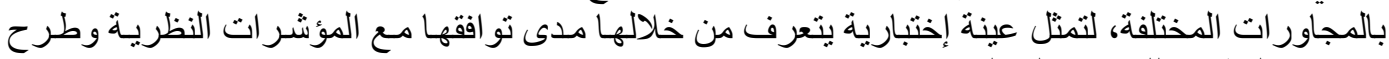
لإمكانية التطوير للمعايير المحلية.

\section{2.رفع وتوصيف الوضع الراهن لمدارس المرحلة الإبتدائية بمدينة أسيوط}

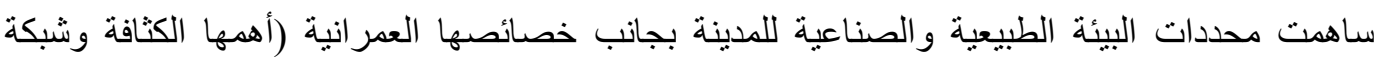

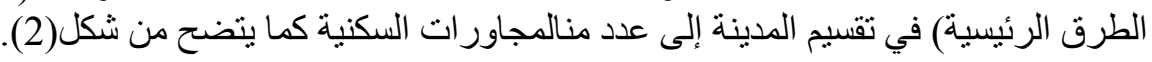
وتمثل متوسط الكثافات بمجاورات المدينة 150 فرد/ فدان، كما وصلت لأكثر من 200 فردم/ فدان

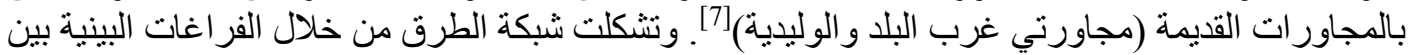

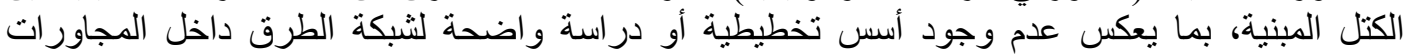

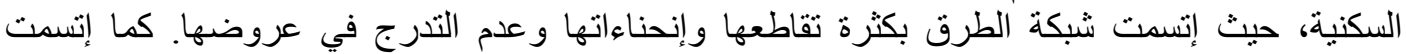

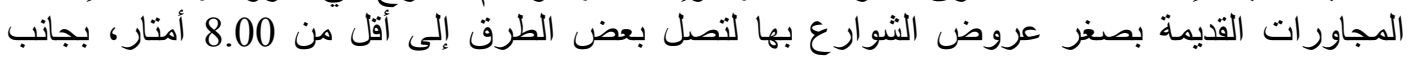

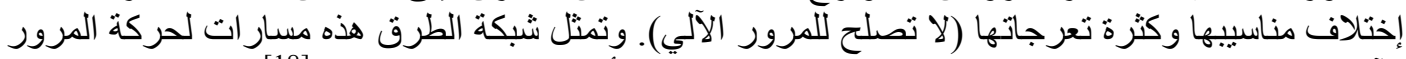

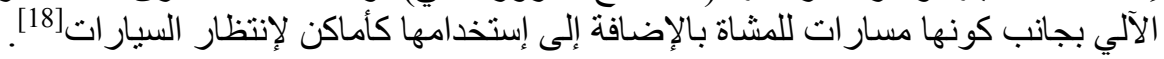


ريم وعظ أمجدعلى، خالد محدد أحد الليثي، محد أبين عبد المجيد ضيف و مجدي محد رضوان

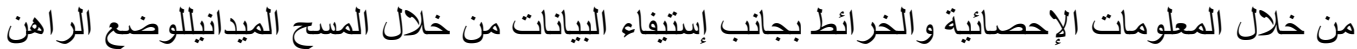

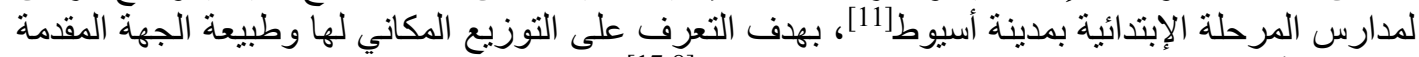

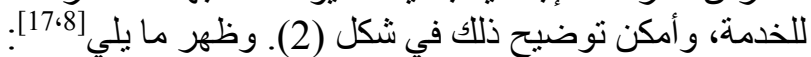

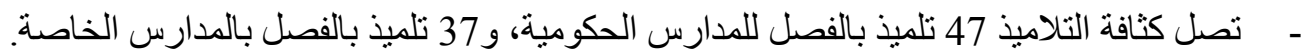

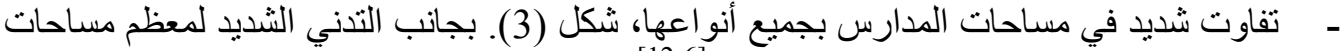

المدارس عن المعايير المصرية للمدن القائمة [6،12]
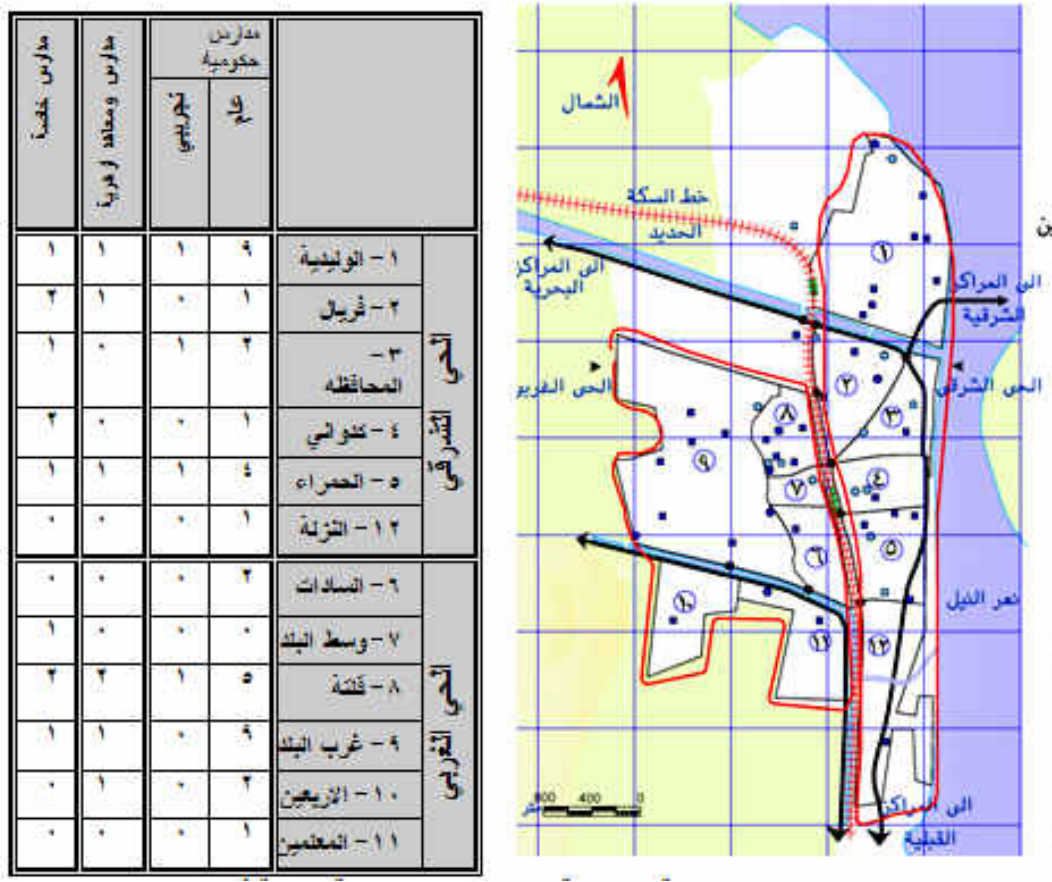

1- الوليدية والمتوقين r r - المريال r- العحانظة 0 - العبراء 7- البسادات ح- وسط الديدية A- ثلتة

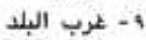

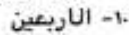
11- ا-1 العملعين rا- نزلة عبدالساة

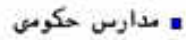

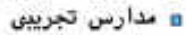

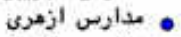
م مدارس خاصة أصري

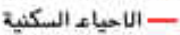
_ - حدود الميجاورات

شكل رقم(2):التوزيع المكاني لمدارس المرحلة الإبتدائية بالمجاورات السكنية بمدينة أسبوط[12]

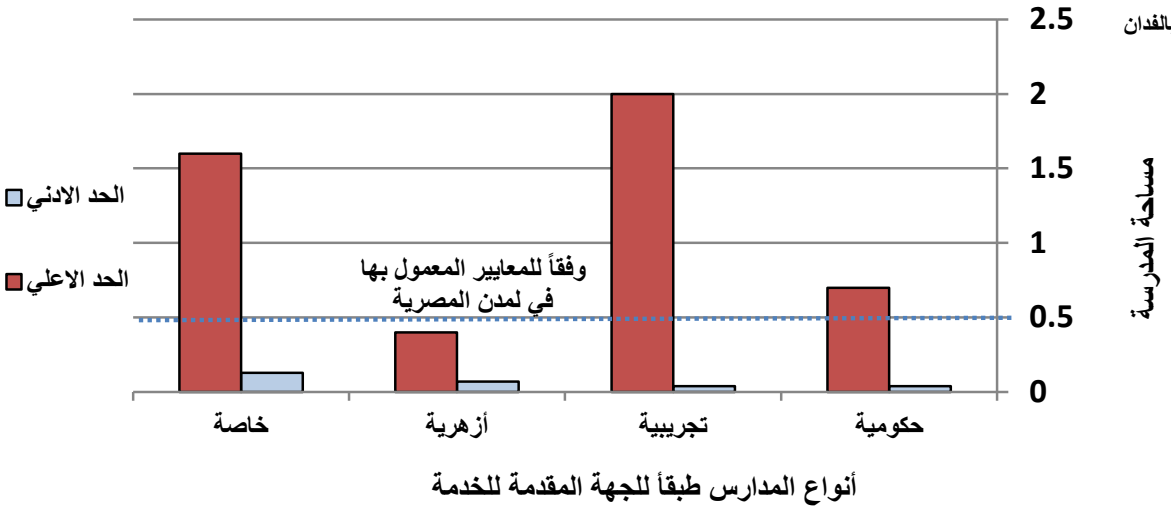

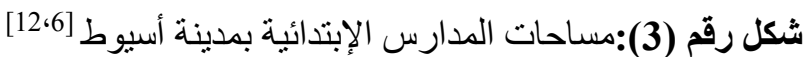

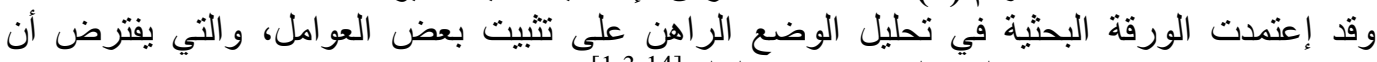

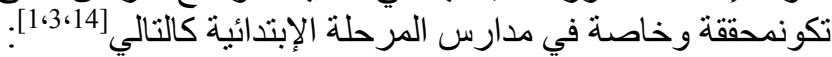
- إعنماد سكان المدينة على المدارس داخل الحيز العمر اني للمدينة. 
- أن المدارس الموجودة كافية لخدمة أعداد الأطفال في سن تللك المرحلة بالمدينة.

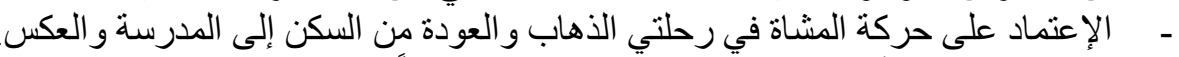

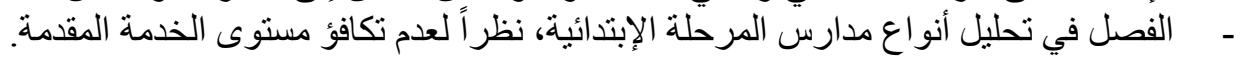

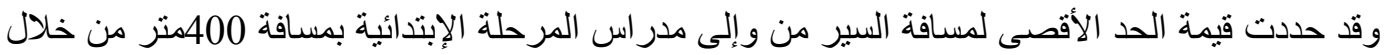

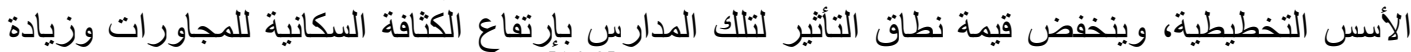

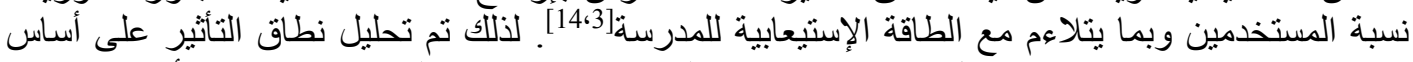

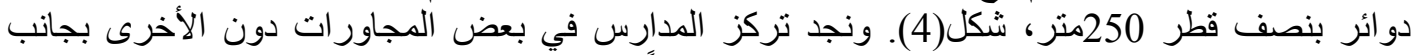

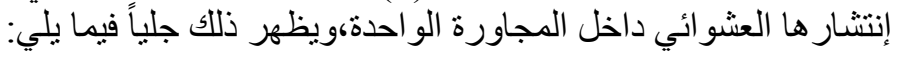

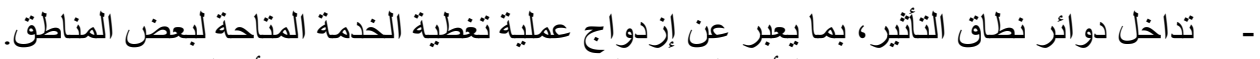

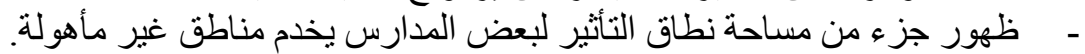

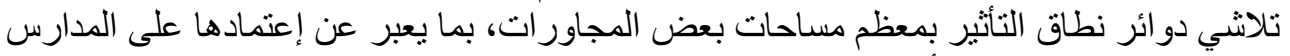

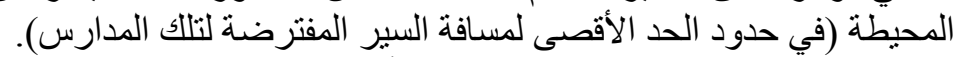

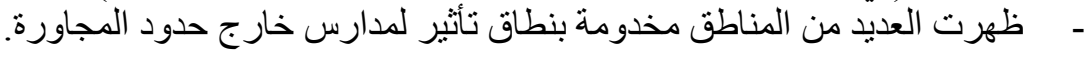

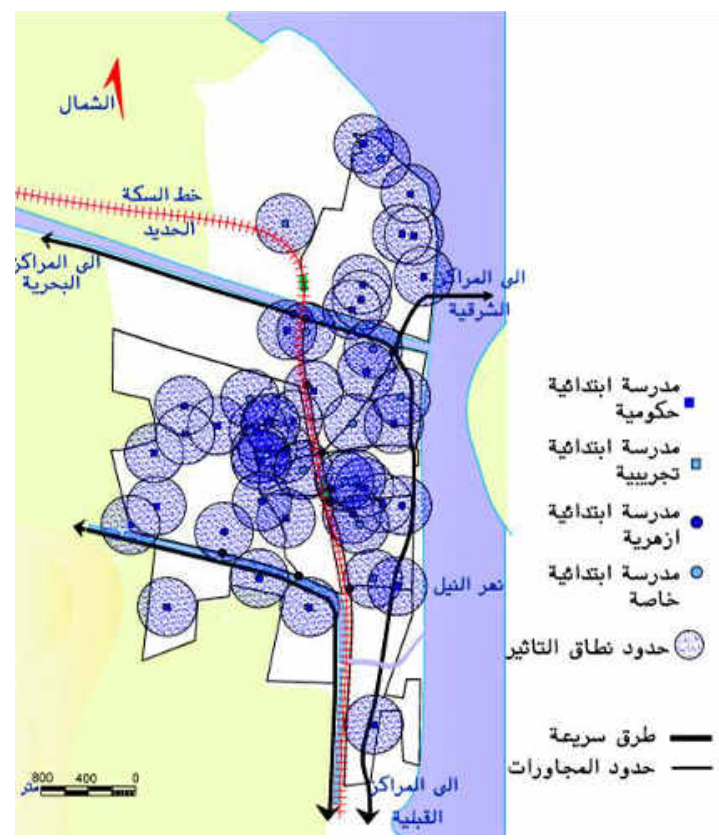

شكل رقم (4):در اسة نطاق التأثير (نق=أق250م) لجميع مدارس المرحلة الإبتدائية بمدينة أسيوط [12]

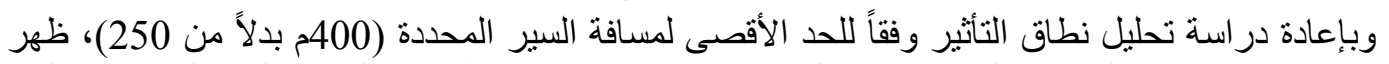

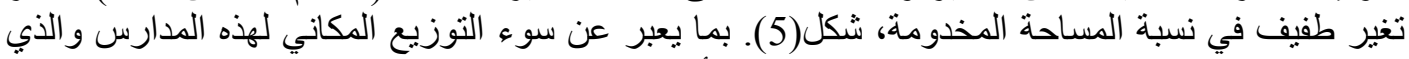

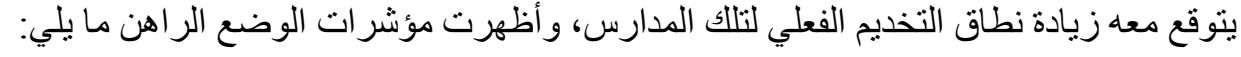

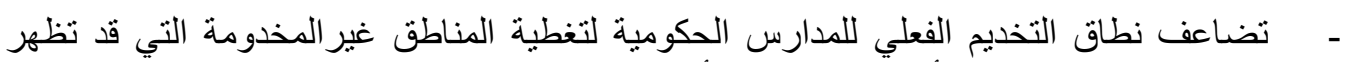

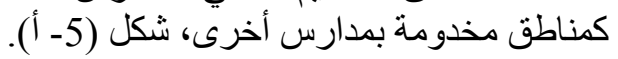

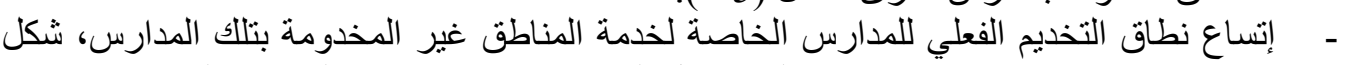
(5- ب)، بما يبين ضرورة الإعتماد على وسائل المو اصلات في رحلات الذهاب الذبان و العودة. 
ريم وعظ أمجدعلى، خالد محدد أحد الليثي، محد أبين عبد المجيب ضيف و مجدي محد رضوان

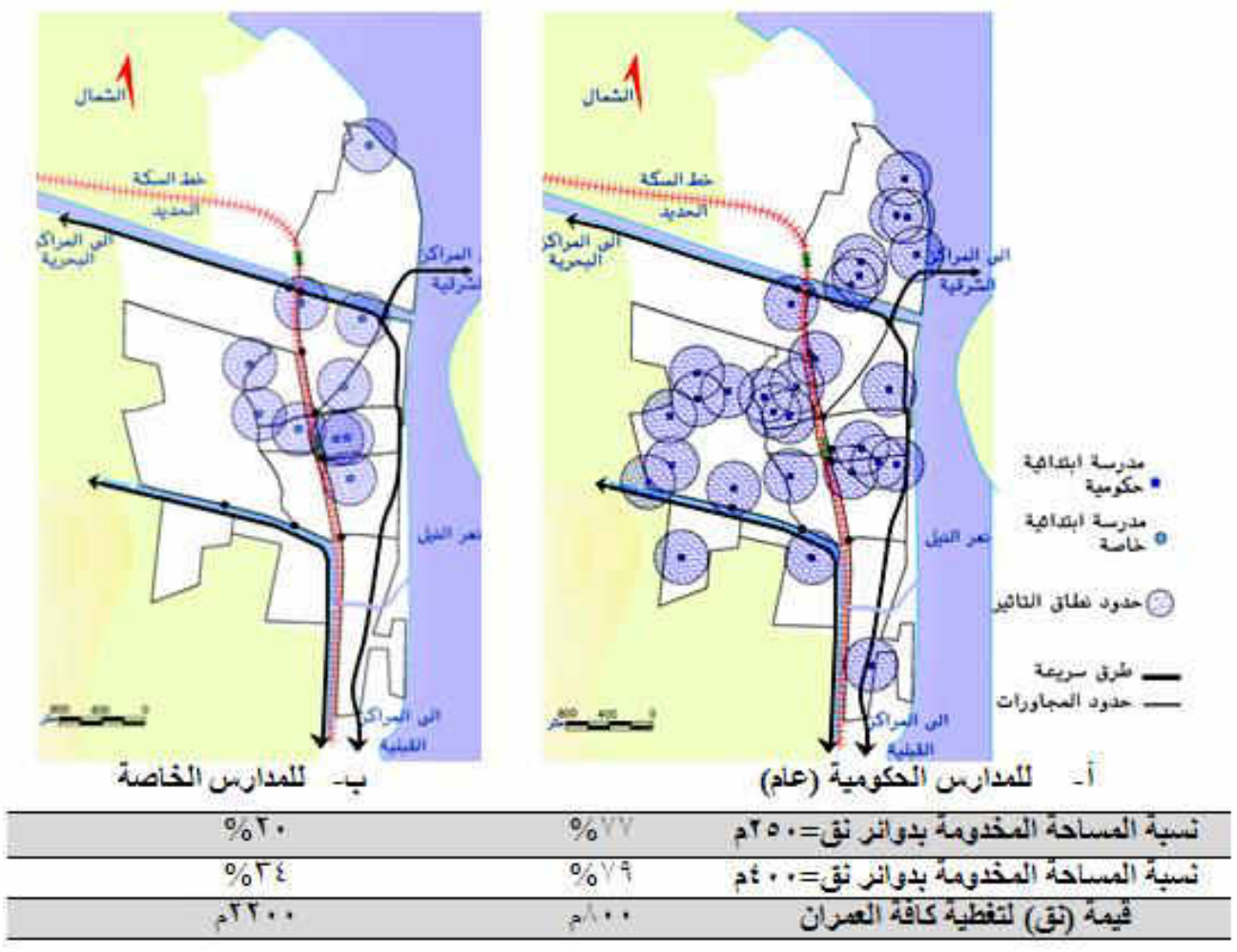

شكل رقم(5):در اسة نطاق التأثنير (نق=250، 400ه) لمدارس المرحلة الإبتدائية بمدينة أسيوط[12] وقد ظهر من تحليل بيانات التلاميذ المقيدين بمدارس المرحلة الإبتدائية ما يلي [19،16]:

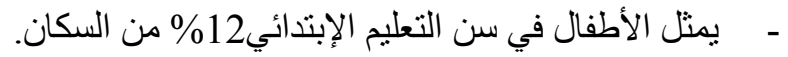

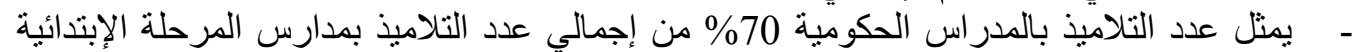
(منها 11\% تلاميذ بمدارس تجريبية).

- تصل نسبة التلاميذ بالمعاهد الأزهرية الإبتدائية 9 \% من من إجمالي التلاميذ بالمرحلة الإبتدائية. ومن خلال تحليل بيانات السكان بالمجاور ات أمكن تحديد إحتياجات السكان من مدارس المرحلة الإنة الإبتدائية

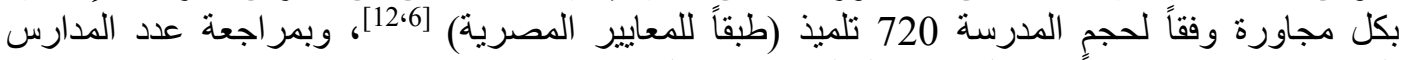
المفترض توفير ها مقارناً بعدد المدارس الفعلية ظهر المهر ما يلي:

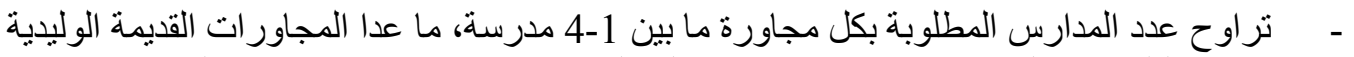

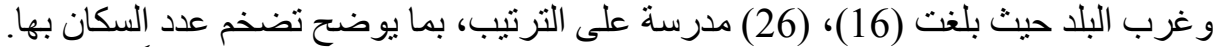
نقص طفيف في إجمالي عدد المدارس الفعلي عن المحدد بالمعايير المصرية وفقاً لمعدلات المدات الهيئة

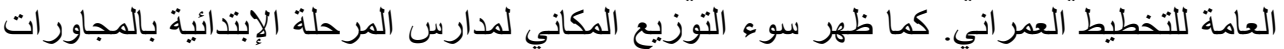

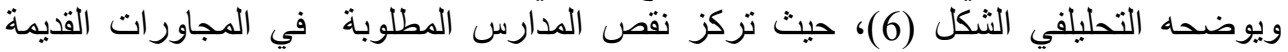

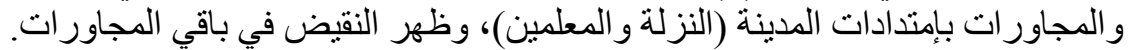

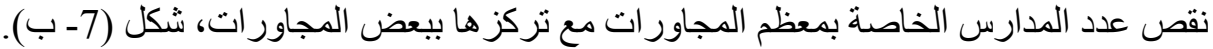

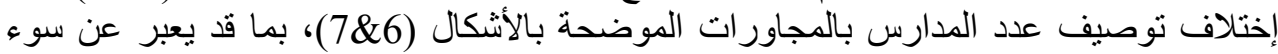
التوزيع المكاني لأنو اع المدارس، أو اختلاف نسب أنواع المدار المدارس المطلوبة بكل مجاورة. 


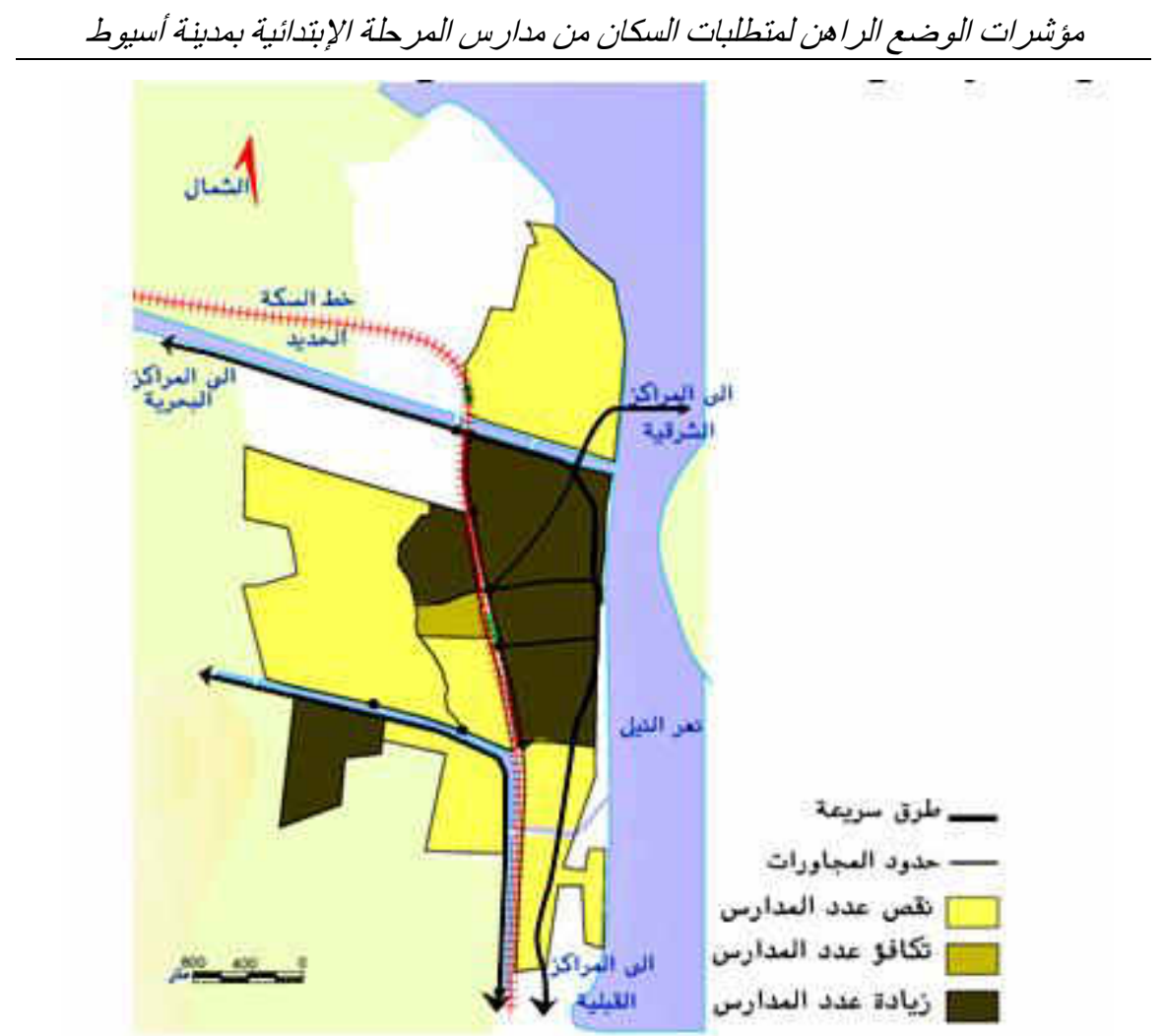

شكل رقم(7):توصيف عدد المدارس المتوفرة بعدد المدارس المحددة من المعايير المصرية بكل مجاورة[12]

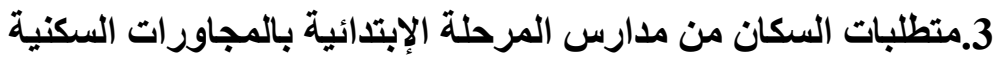

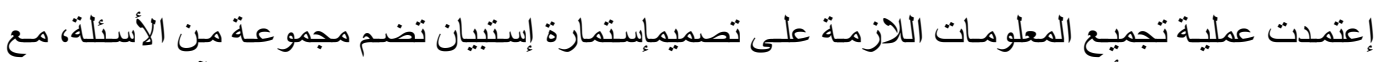

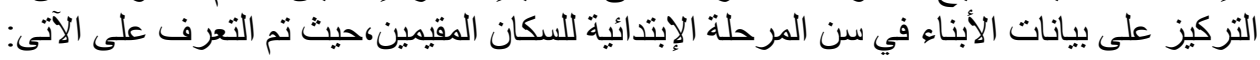
-

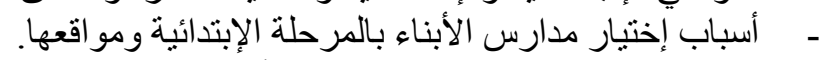

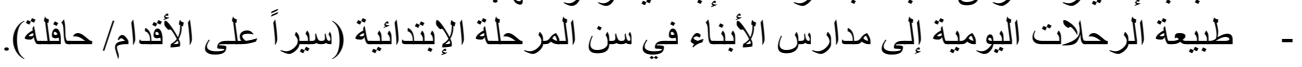

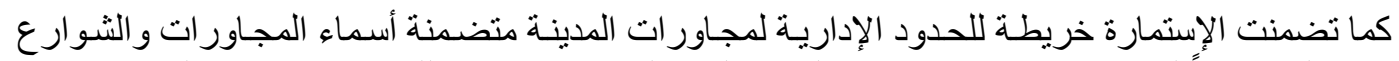

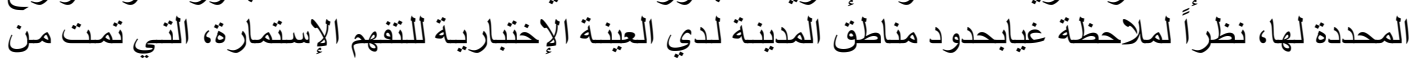

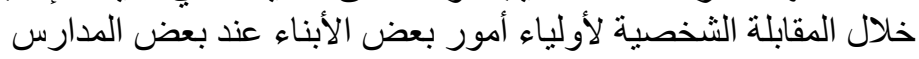

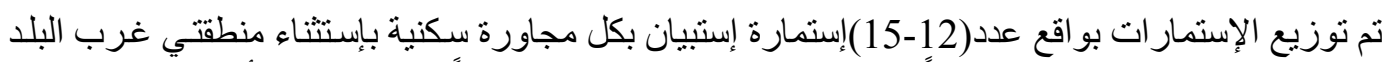

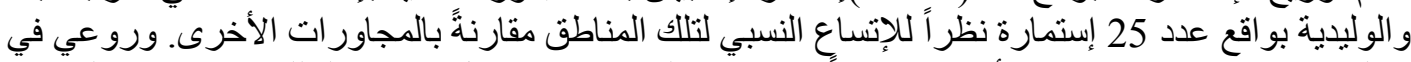

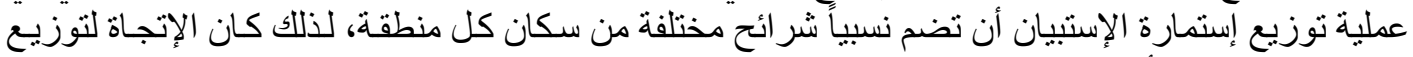

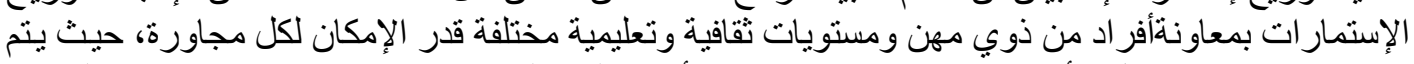

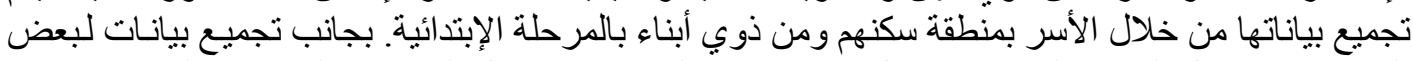

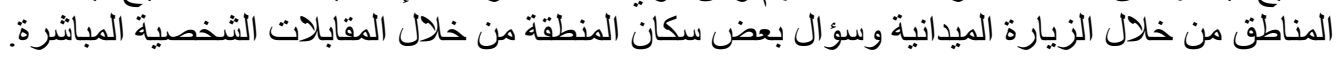

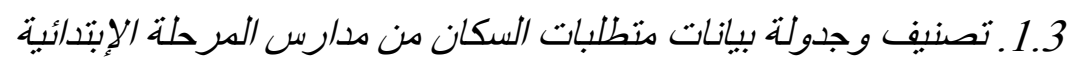

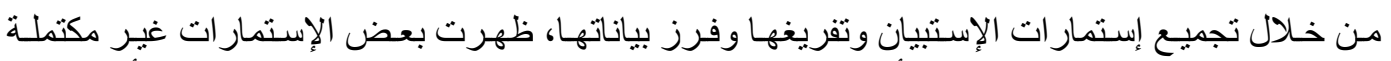

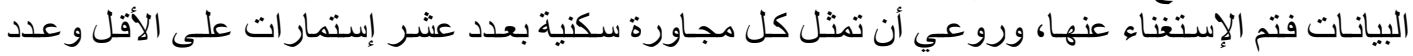

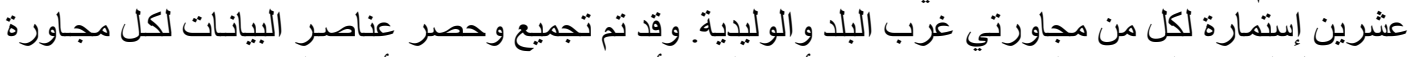

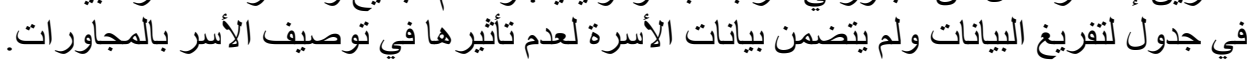




$$
\text { 2.3. تحلبل بيانات متطلبات السكان من مدارس المرحلة الإبتدائية }
$$

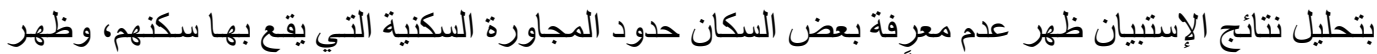

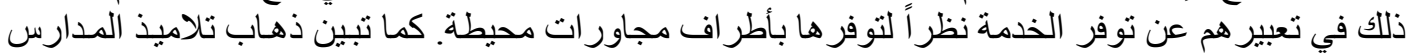

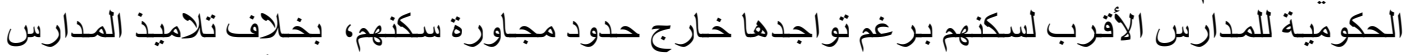

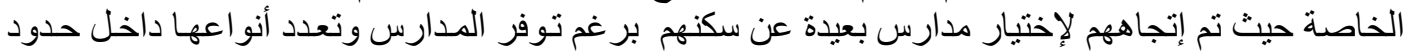
مجاورة سكنهم. وتم تحديد نسب البيانات لكل عنصر ، وأمكن تصنيفها في النقاط التالية:

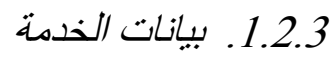

تمثلت عناصر توصيف مدارس المرحلة الإبتدائية في النقاط التالية:

-

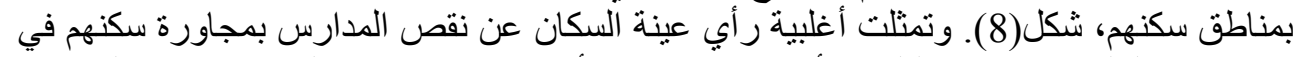

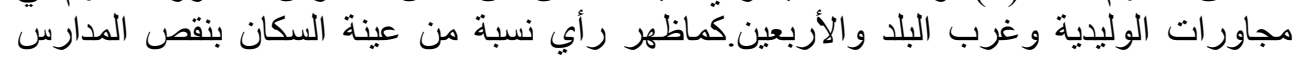

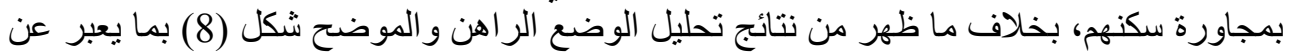

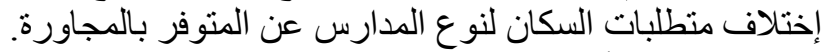

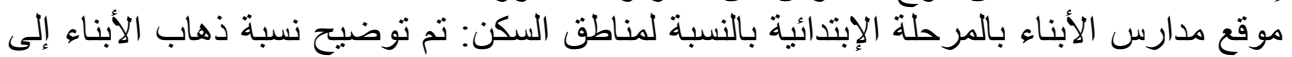

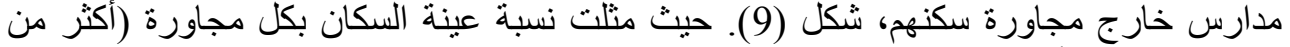

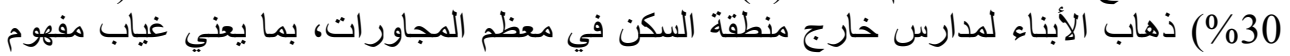

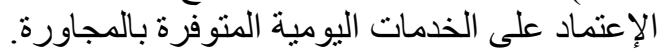

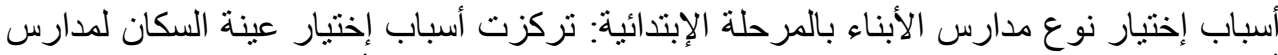

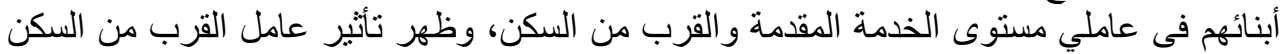

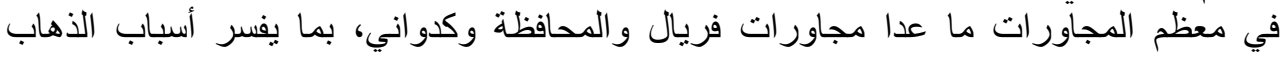
لمدارس خارج منطقة السكن بالرغم من نو افر الخدمة.

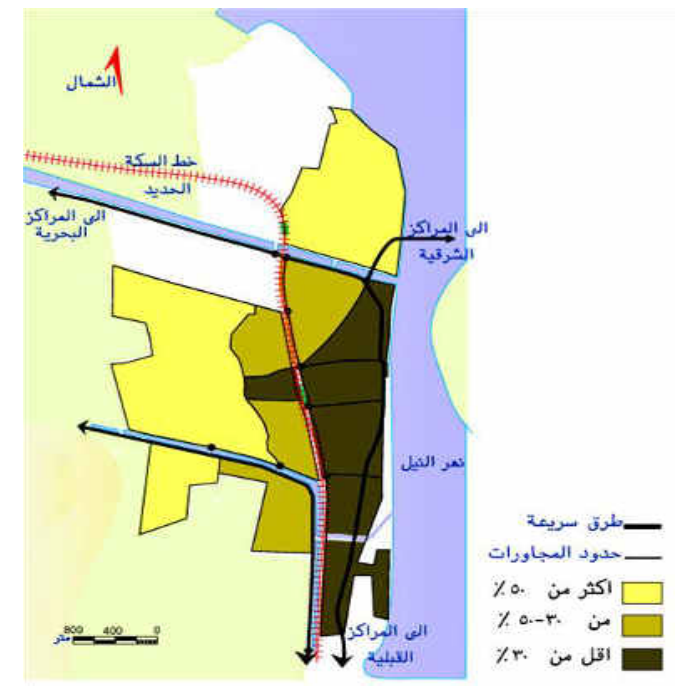

شكل رقم (8): نسبة رأي الأسر لنقص المدراس الإبتدائية بالمجاورات السكنية بمدينة أسيوط 


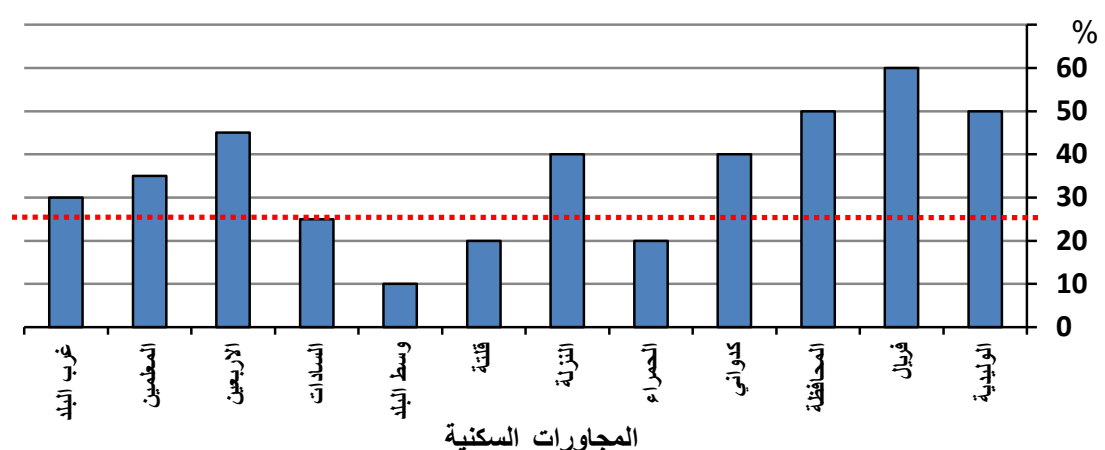

شكل رقم (9): نسبة ذهاب الأبناء لمدارس خار ج منطقة السكن للمجاور ات السكنية بمدينة أسيوط

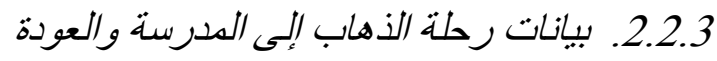

$$
\begin{aligned}
& \text { أمكن توصيفها في النقاط التالية: }
\end{aligned}
$$

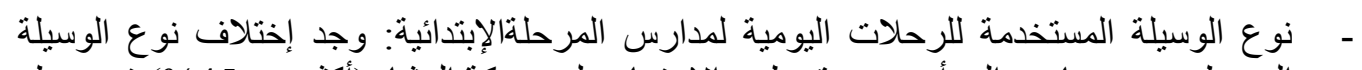

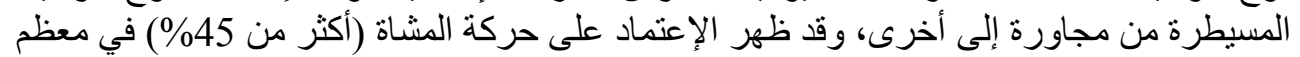

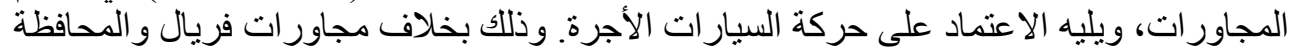

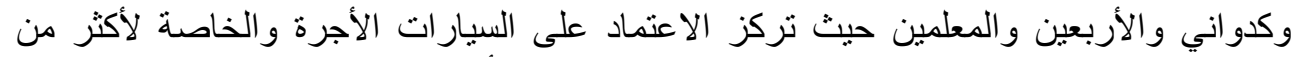

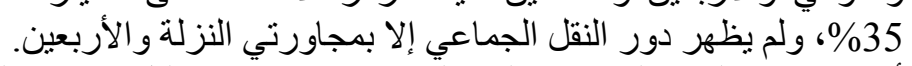

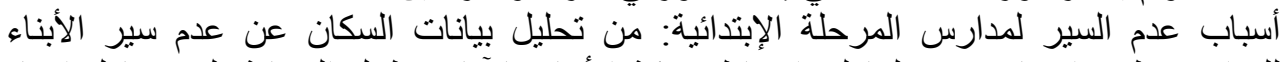

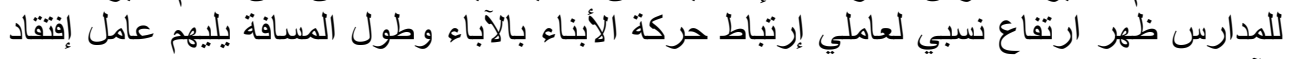

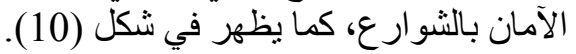

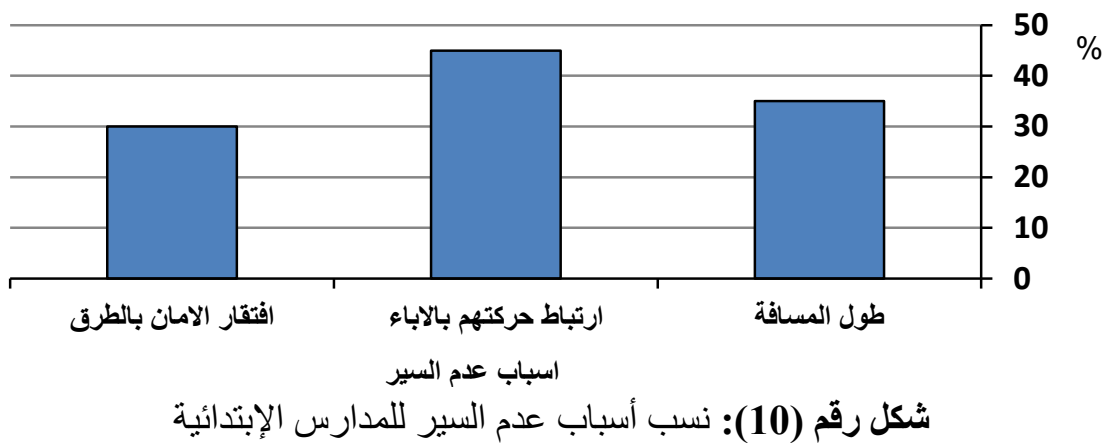

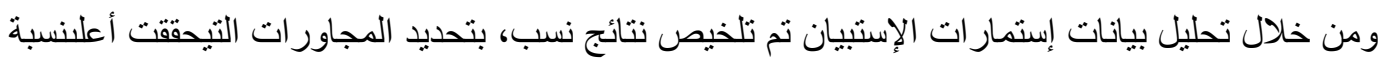

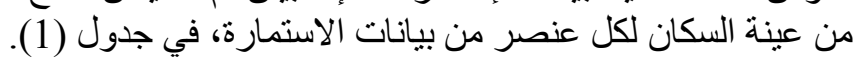


ريم وعظ أمجدعلى، خالد محدد أحد اللبيّي، محد أيبن عبد المجيد ضيف و مجدي محد رضوان

جدول (1):توصيف مؤشر ات إرتفاع نسبة بيانات الإسنمار ات للمجاورة لكل عنصر

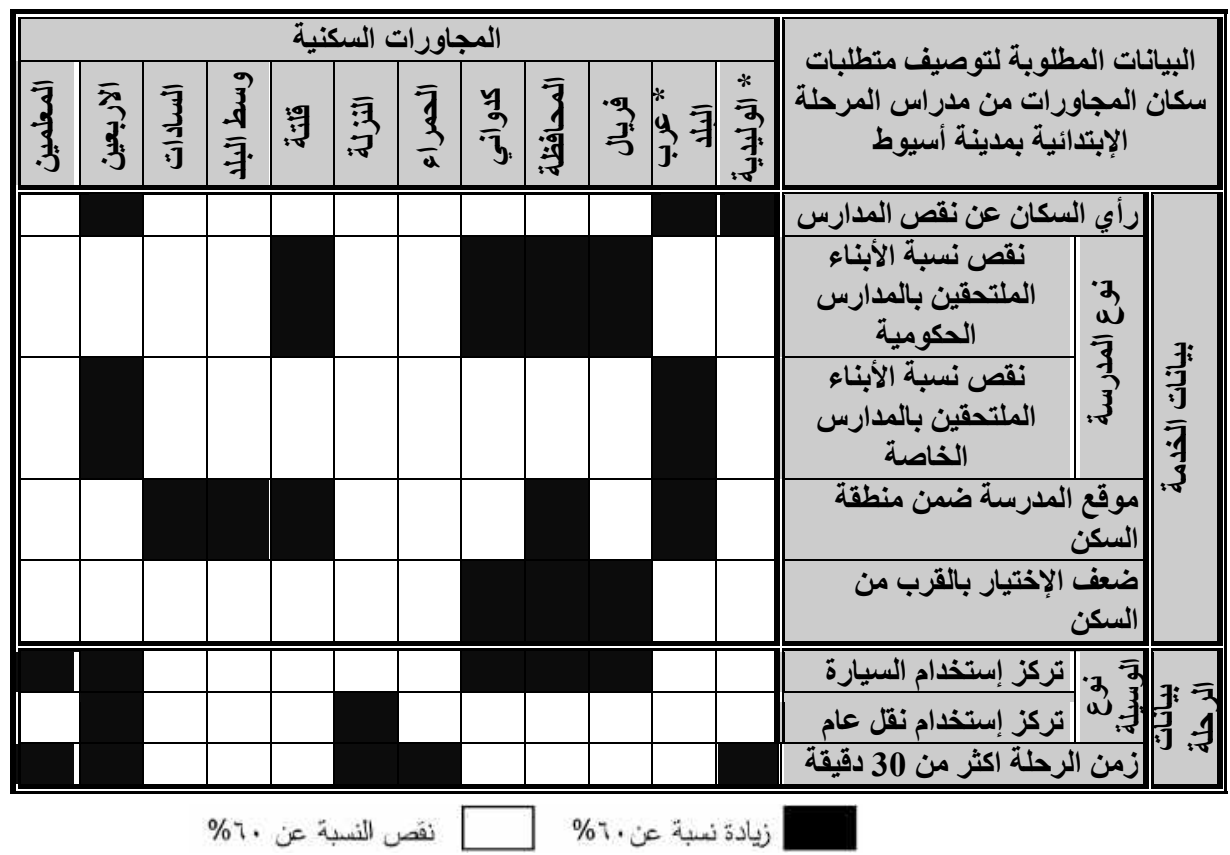

4. توصيف متطلبات السكان من مدارس المرحلة الإبتدائية الحكومية بالمجاورات السكنية أظهرت نتائج تحليلات الإستبيان بكل مجاورة، إختلاف في نسبة إعتماد السكان على المدارس الإبتدائية

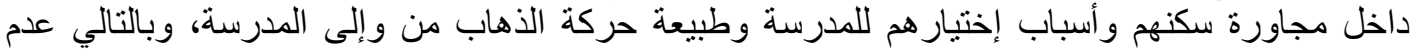
ملاعمة المحددات العامة لإحتياجات السكان من مدارس المرحلة الإبتدائية بالمجاورة الإنة السكنية. وبناءً عليه تم

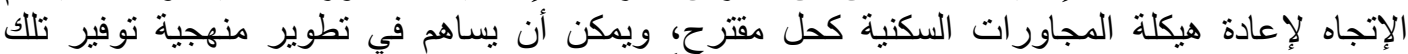

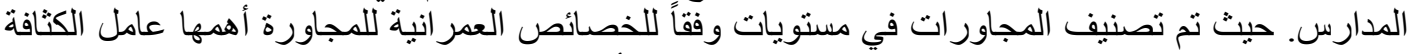

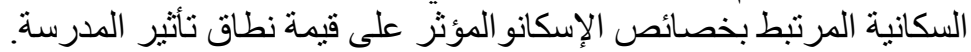

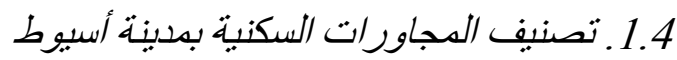
أظهر تحليل الوضع الر اهن التفاوت الثديد في إحتياجات السكان من مدارس المرحلة الإبتدائية بالمجاورة لإختلاف حجم المجاور ات. لذللك تم التحقق من تجانس حجم المجاورات من حيث التب عدد سكانها ومساحتها،

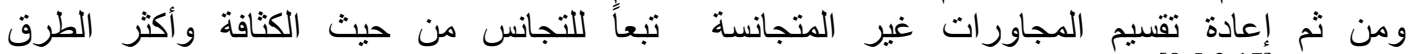

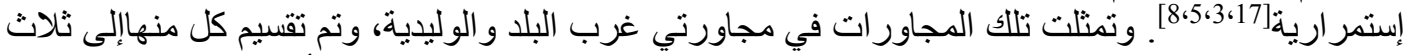

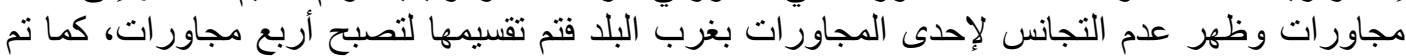

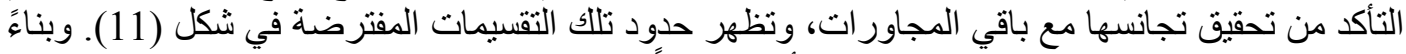

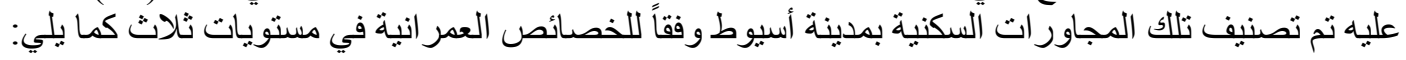




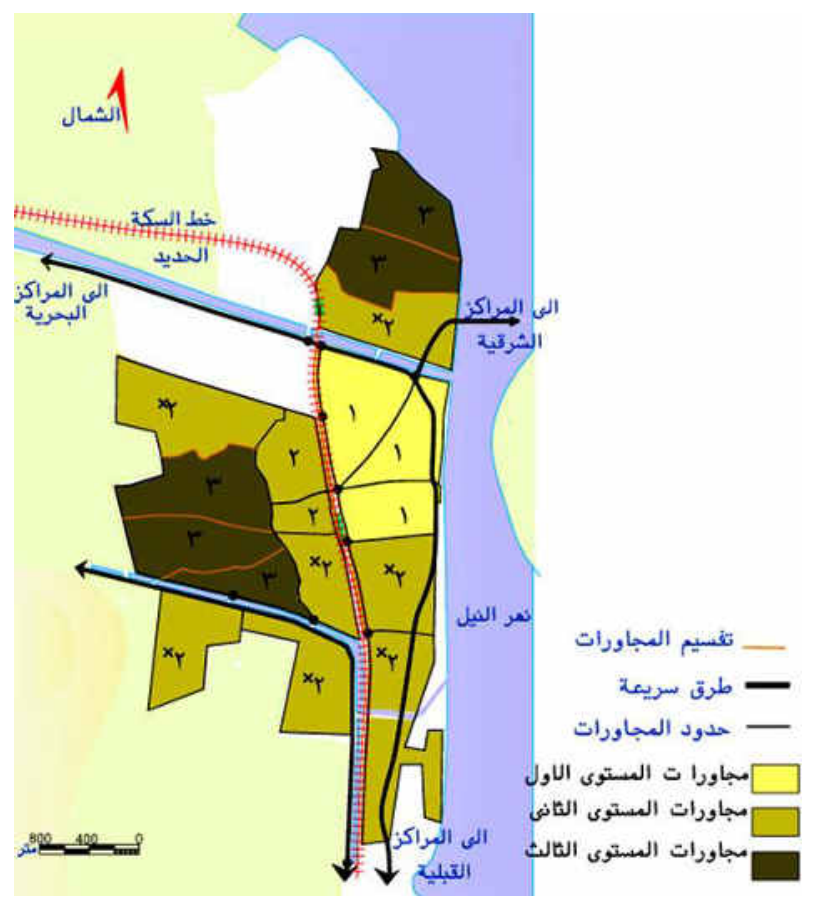

شكل رقم (11):حدود تقسيم مستويات المجاورات بمدينة أسيوط[12]

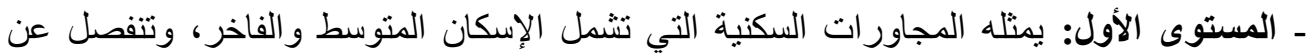

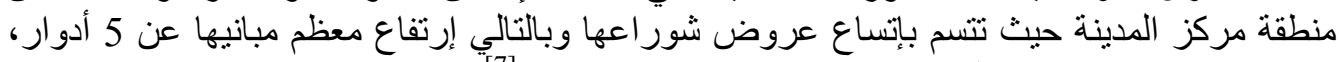

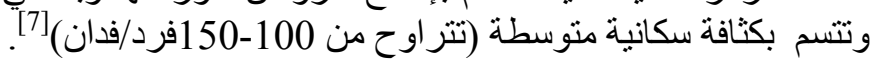

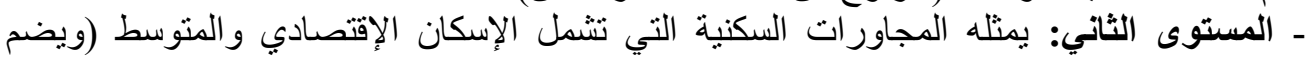

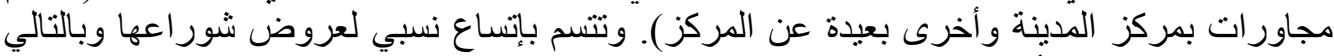

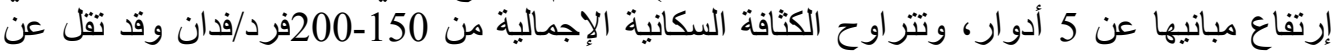
150فرد/فدان بمجاورات الإمتدادات العمرانية، ويوضح شكل (11) مستويات المجاورات بمدينة الإنة

ـ المستوى الثالث: يمثله المجاورات السكنية التي يسكنها ذوي الدخل المنخفض والإقتصادي، وتتمثل

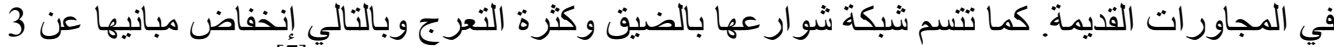

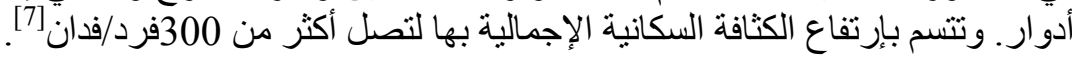


ريم و عظ أمجدعلى، خالد محدد أحد الليثي، محد أيبن عبد المجيد ضيف و مجدي محد رضوان

جذول (2):توصيف لمستويات المجاورات ونسب التلاميذ بالمرحلة الابتدائية بالمدارس الحكومية

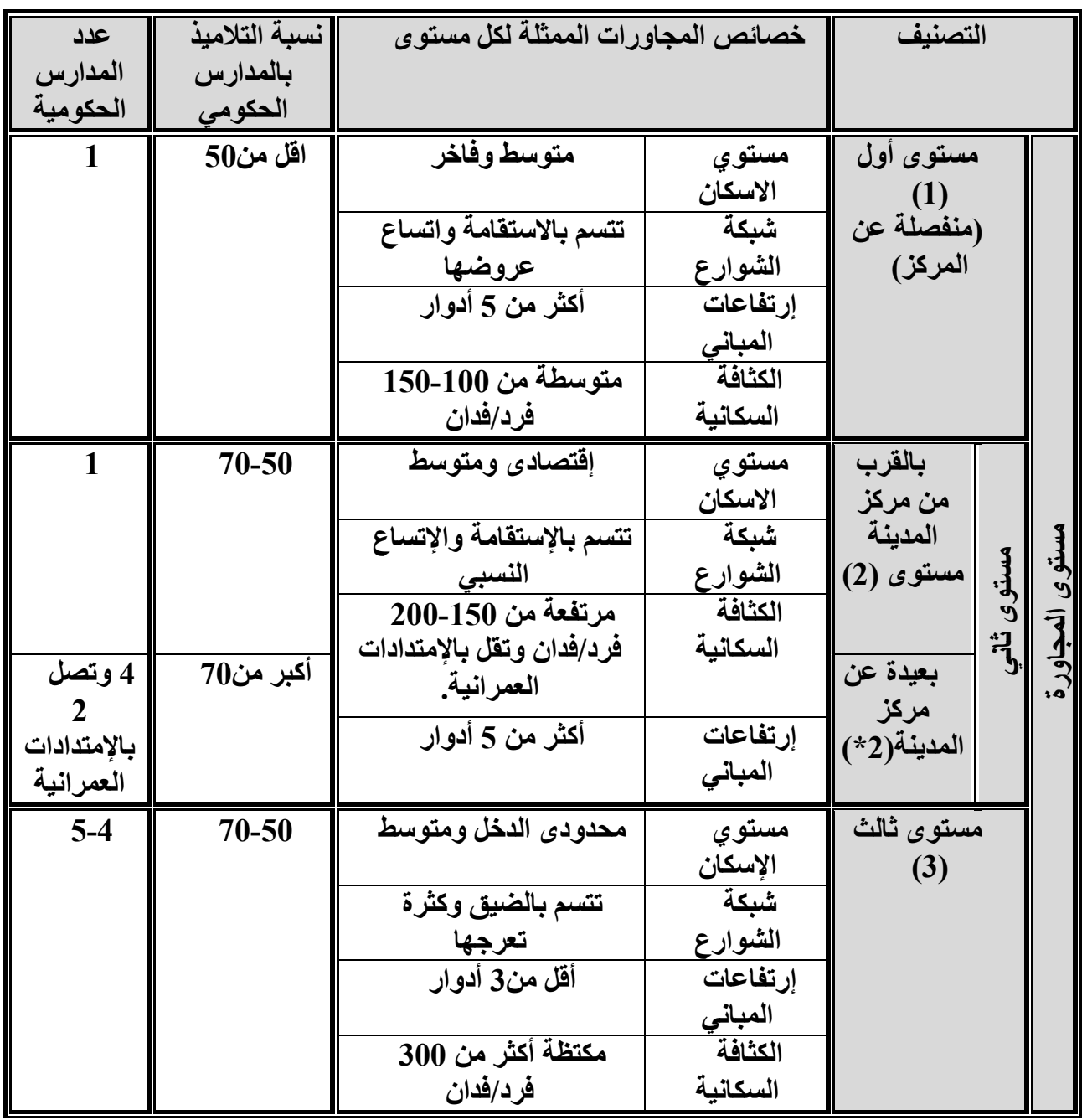

2.4. متطلبات السكان من مدارس المرحلة الإبتدائية بدجاورات مدبنة أسبوط

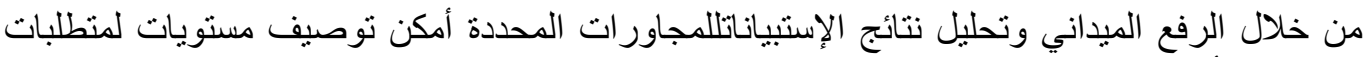

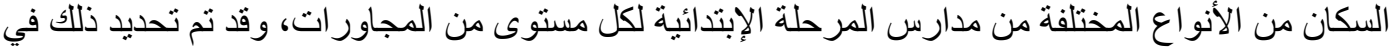

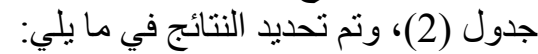

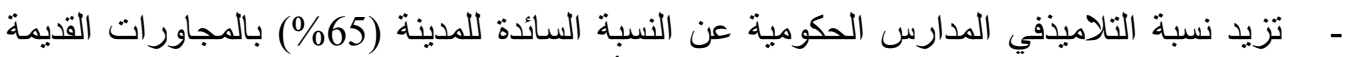

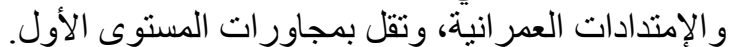

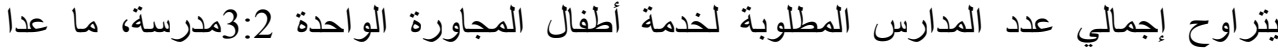

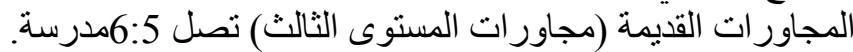

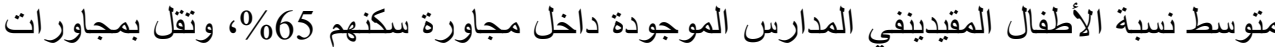
المستوى الأول بغض النظر عن توفر الفونف الخدمة وتنو عها. 


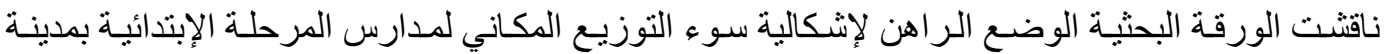

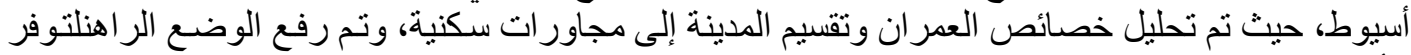

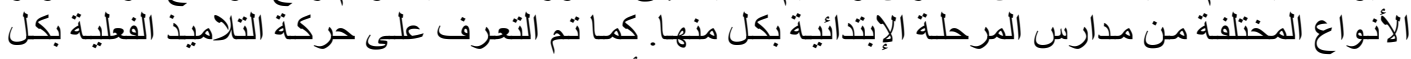

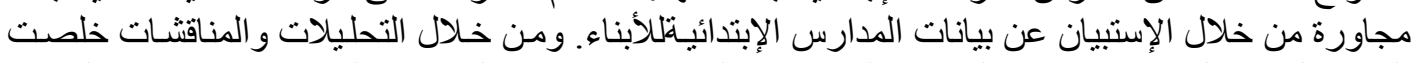

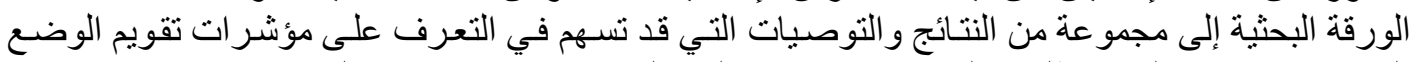

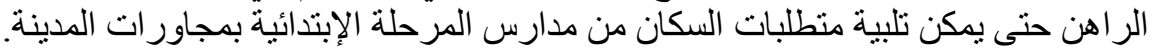

1.5

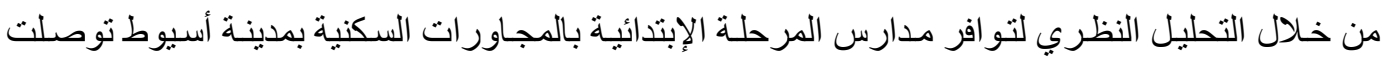

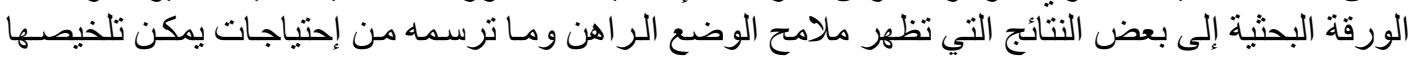
فيما يلي:

التفاوت الثديد في حجم المجاورات من حيث مساحتها و عدد سكانها، مع غياب الأطر التخطبطية

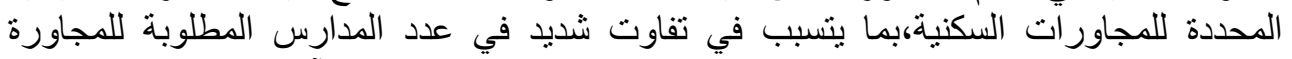

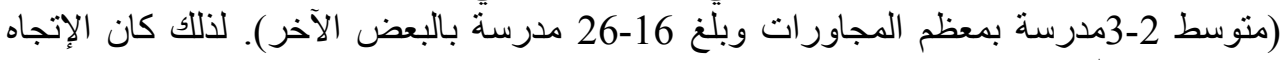

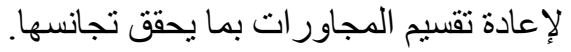
ظهور إنتنار وتوزيع عفوي للمدارس دارئ داخل المجاورة، بما تسبب في تداخل نطاق التأثير للمدارس

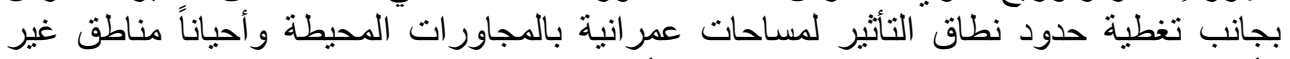

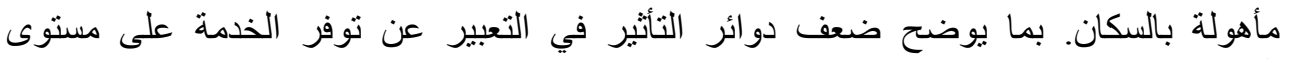
المجاورة. ظهرت المدارس غير الحكومية في بعض المجاورات دون الأخرى، بما بصعب معه در اسة توفر المدارس على مستوى المجاورة فقد يغطى نطاق نأثير ها النظري مساحات عمر انية بمجاورات

محيطة. يغطي نطاق التأثير النظري لإجمالي مدارس المرحلة الإبتدائية 80\% من العمران، وأغلبها

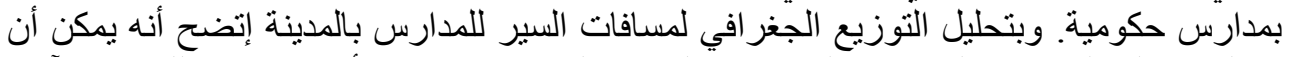

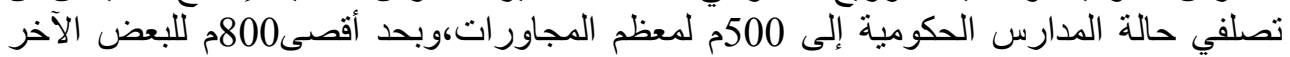

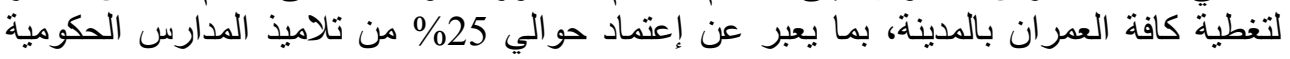

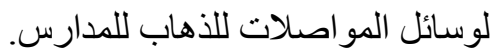

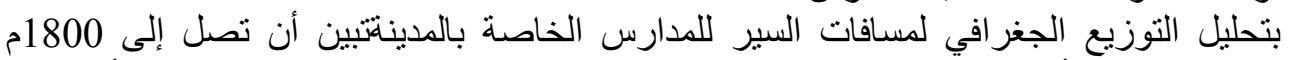

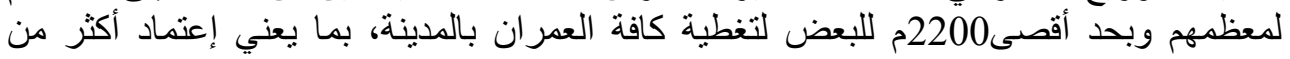

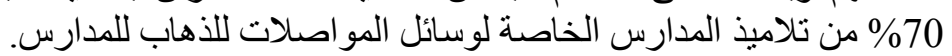

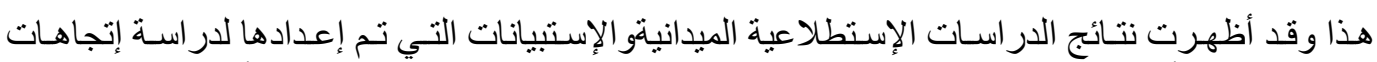

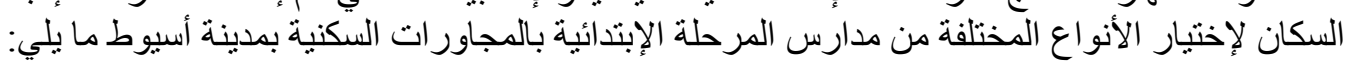
عدم إدر الك حدود المجاور اتلدى السكان أثر على تعبير هم عن نوفر الخدمة بمجاورة سكنهم، إعتماداً على مدارس بمجاور ات محيطة.

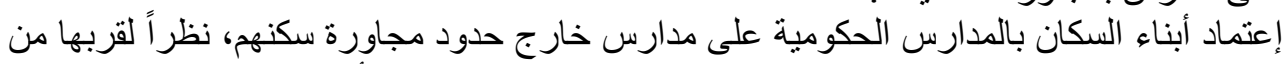

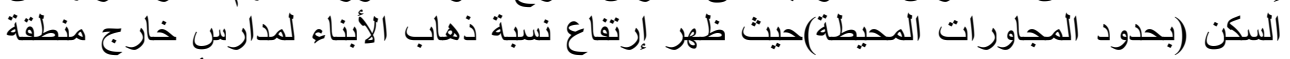

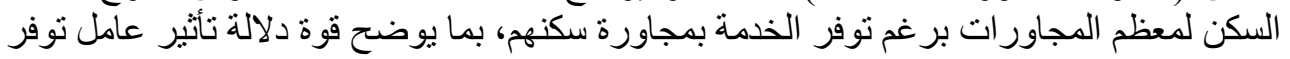

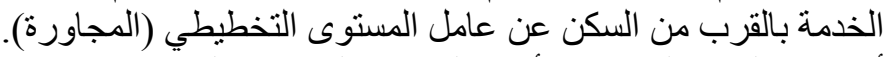

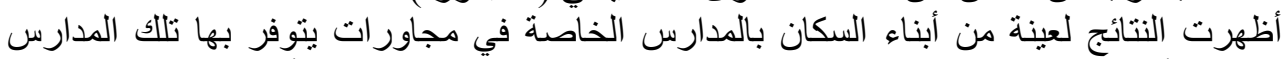

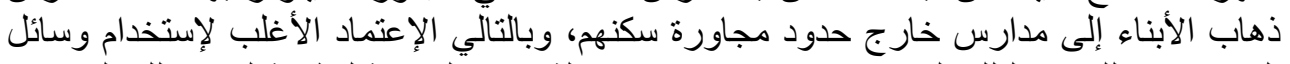

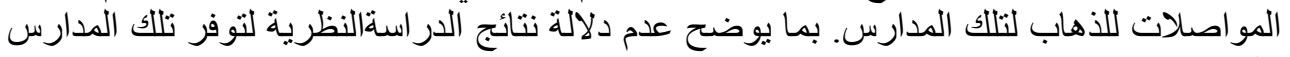


ريم وعظ أمجدعلى، خالد محدد أحد الليثي، محد أبين عبد المجيد ضيف و مجدي محد رضوان

- يقل زمن الرحلة للمدارس الخاصة برغم نو اجدها خارج مجاورة السكن، نظر اً للإعتماد على النقل

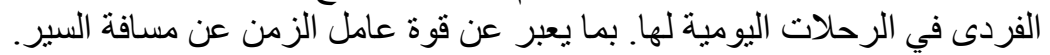

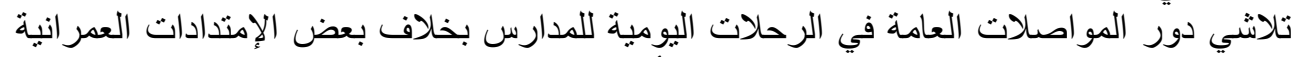

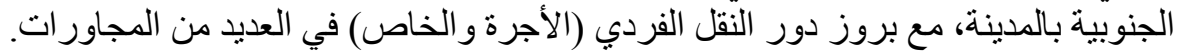

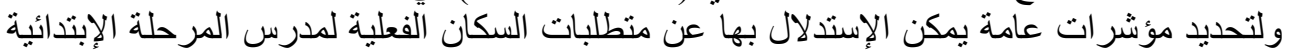

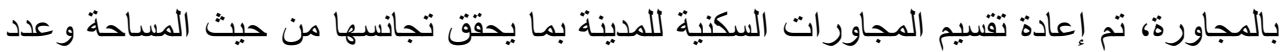

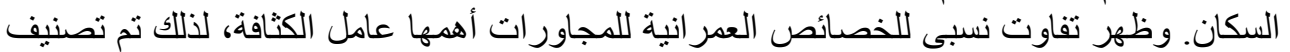
المجاورات في ثلاث مستويات. وبتحليل متطلبات السكان الفعلية بمستويات المجاورات الهية السكنية ظهر ما يلي: تركزت عينة الأبناء لمدارس خاصة في مجاورات المستوى الأول (منخفضة الكثافة وتقع بمركز المدينة). تركزت.

تركزت عينة الأبناء لمدارس حكومية في مجاورات المستوى الثالث (القديمة ومرتفعة الكثافة). 2.5

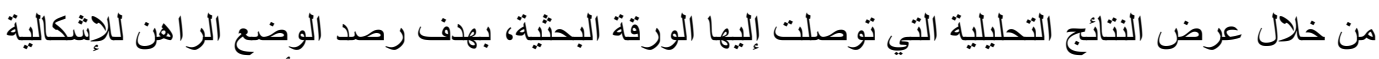

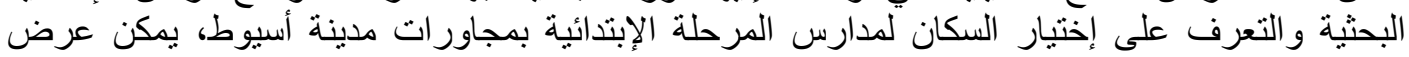
التوصيات التي خلصت إليها الورقة البحثية في النقاط التالية:

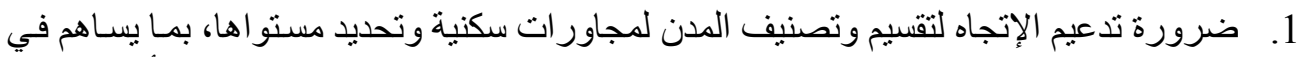

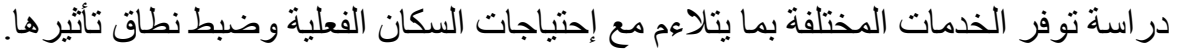

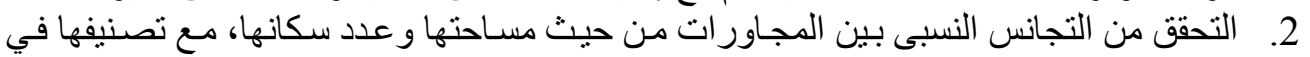

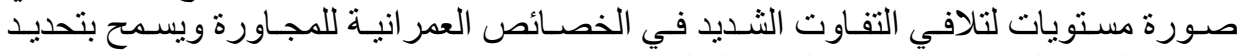

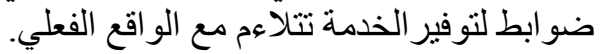

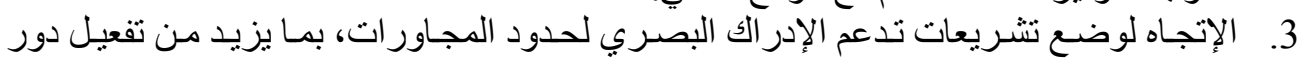
المجاورة لسكانها.

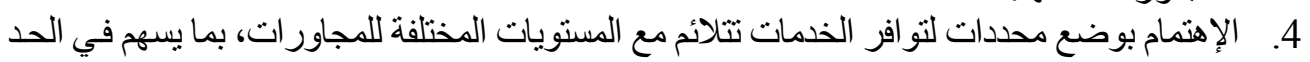

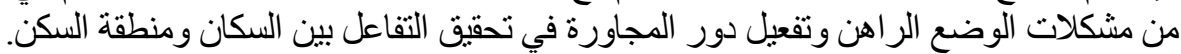

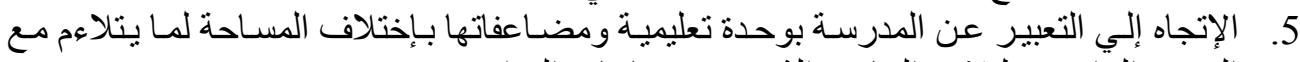

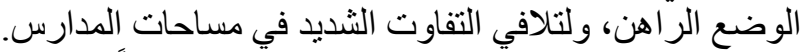

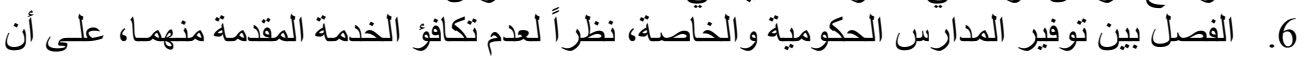

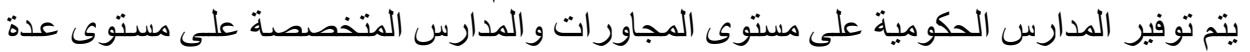

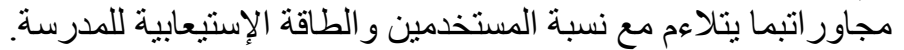

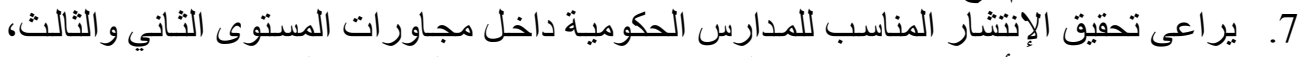

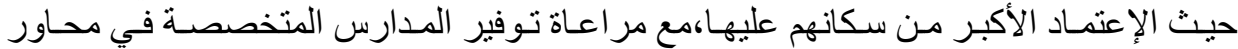

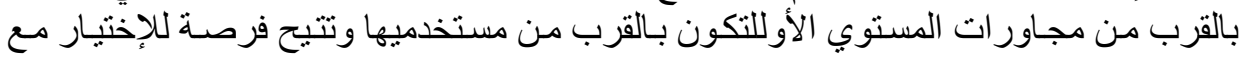
الحد من مشكلات الحركة.

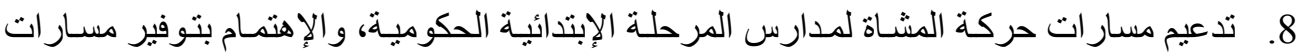

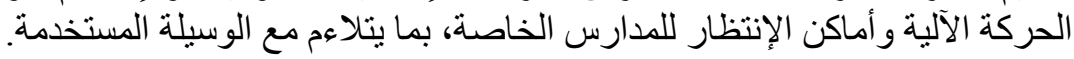

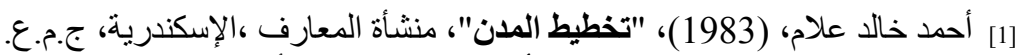

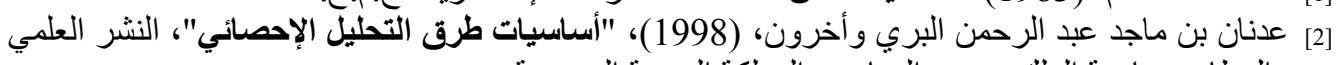
و المطابع، جامعة الملك سعود، الرياض، الرئ المملكة العربية السعودية. 
[3] [نتر عبد العال أبو قرين، (1997)، "أسس ونظريات التخطيط العمراني"،جامعة المنيا، المنيا، ج.م.ع.

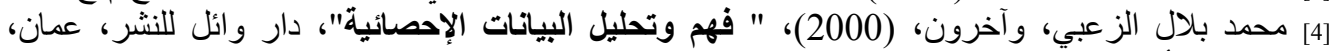
المملكة الأردنية.

[5] العيئة العامة للأبنية التعليمية، (1992)، "دليل توظيف المواقع المتاحة وبدائل تخطيط المواقع"، الهيئة

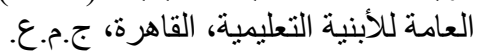

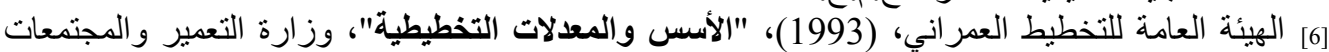

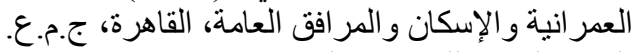

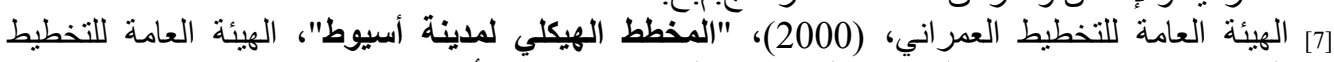

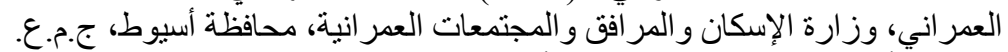

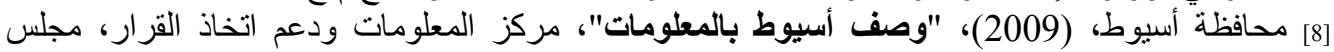
الوزراء، القاهرة، ج.م.ع. [9] علي محمد رضا الحيدري، (1986)، "حدود الكثافة البنائية والسكانية في المناطقالحضرية"،

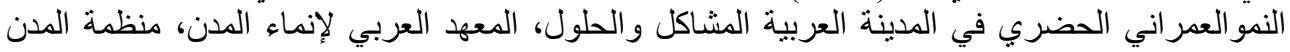

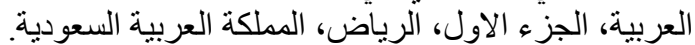

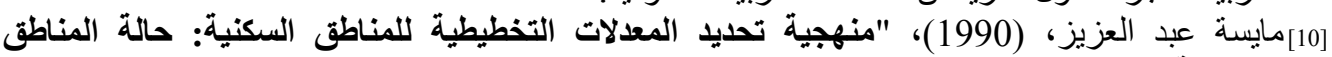

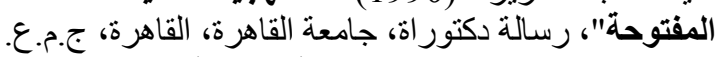

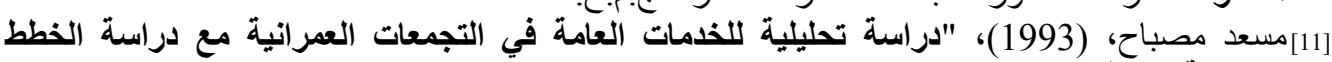

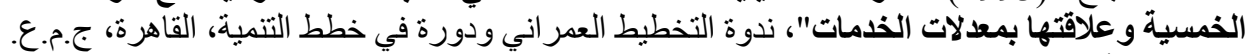

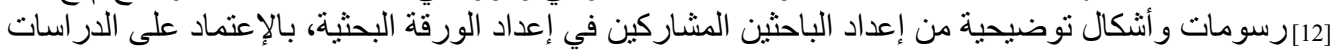

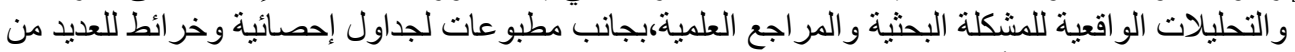

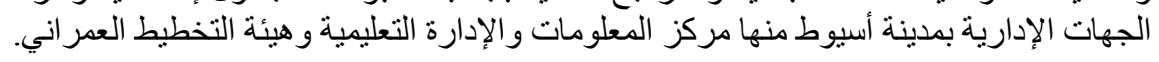

[13]DE Chiara G, (1975), "Urban Planning and design criteria", Van Nostrand Renhold, London.

[14]Jacques Hallak, (1975), "Planning The location of schools", International Institue for Educational planning, London.

[15]http:// www.capmas.gov.eg/ interanet-egy.htm ,(2009/June)

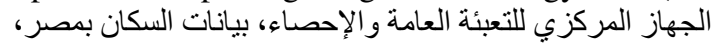

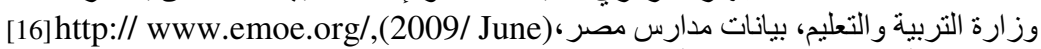

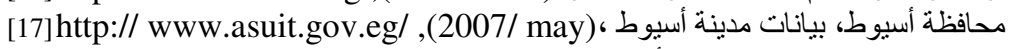

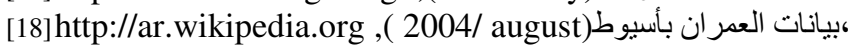

[19] http:// www.egyptschool.com, (2007/ may) ،يانات مدارس مصران بأسوطر 


\title{
INDICATORS OF THE CURRENT STATUS OF POPULATION REQUIREMENTS OF ELEMENTARY SCHOOLS IN ASSIUT CITY
}

\author{
Reem Wazz Amgad Ali ${ }^{1}$, Khaled Mohamed Ahmed El-lithy ${ }^{2}$, MohamedAyman Daef ${ }^{3}$, \\ Magdy Mohamed Radwan ${ }^{4}$
}

\begin{abstract}
Educational services in Egyptian cities are characterized by uneven level of service, where the disparity in social, economic and cultural aspects of population has contributed to service multiplicity and diversity levels to meet the population requirements. This has led to the spread of different spontaneous types of Elementary Schools in residential neighborhoods within the city, and without any planned consideration of the geographical distribution to fulfill the needs of neighbourhood populations. Specific types of Educational services are found in certain neighbourhoods, and not all. Using alternative types of transportation has encouraged the avoidance to choose closest schools to housing, and to focus on the appropriate level of service. In light of increasing diversity of primary schools, significance of this study is to reveal the requirements of population by extrapolating the current status of those schools, which could contribute to developing planning criteria for the Egyptian city.

The methodology adopted in this paper is based on the assessment of population requirements, and the movement of pupils to Elementary Schools in Assiut City. Analysis of the current state of residential neighborhoods and the characteristics of available primary schools in each of them, besides the analysis of walking distances as an indicator of pupils movement to and from schools have been crucial to the adopted methodological approach. The research has used extrapolation methods based on a small sample of population from different neighborhoods as an indicator of population opinion about available Elementary Schools in the corresponding housing communities, and the movement of their children to schools.

The paper is aimed at arriving to specific criteria which can be used to optimize the movement of pupils to and from Elementary Schools in residential neighborhoods in Assiut City. Socio-economic levels for residential neighborhoods and the social structure of its population, has been taken into account throughout the analysis. Pupils' movements to the different types of schools have been mapped in field-work study and questionnaire design, thus allowing the consideration of both social structures and location of schools relative to neighborhoods to be taken as well.
\end{abstract}

The paper is concluded by defining a set of standards and controls that could express the nature of the actual movement of pupils to and from schools. Those represent the indicators that can be utilized - as well - to evaluate the current status of Elementary Schools distribution in Assiut City.

\footnotetext{
${ }^{1}$ Lecturer Assistant, Department of Architecture, Faculty of Engineering, University of Assiut, Assiut, Egypt

${ }^{2}$ Assistant Professor, Architecture and Planning, Department of Architecture, Faculty of Engineering, University of Assiut, Assiut, Egypt

${ }^{3}$ Associate Professor, Urban and Regional Planning, Department of Architecture, Faculty of Engineering, Assiut University, Assiut, Egypt

${ }^{4}$ Professor of Architecture and buildings Physics Department of Architecture, Faculty of Engineering, Assiut University, Assiut, Egypt
} 